\title{
Morphology and formation ages of mid-sized post-Rheasilvia craters - Geology of quadrangle Tuccia, Vesta
}

\author{
T. Kneissl ${ }^{\text {a,* }}$, N. Schmedemann ${ }^{\text {a }}$, V. Reddy ${ }^{\text {b,f }}$, D.A. Williams ${ }^{\text {c }}$, S.H.G. Walter ${ }^{\text {a }}$, A. Neesemann ${ }^{\text {a }}$, G.G. Michael ${ }^{\text {a }}$, \\ R. Jaumann ${ }^{d}$, K. Krohn ${ }^{\text {d }}$, F. Preusker ${ }^{\text {d, T. Toatsch }}{ }^{\text {d }}$, L. Le Corre ${ }^{\text {b,f }}$, A. Nathues ${ }^{b}$, M. Hoffmann ${ }^{\text {b }}$, M. Schäfer ${ }^{\text {b }}$, \\ D. Buczkowski ${ }^{\text {e }}$, W.B. Garry ${ }^{\mathrm{f}}$, R.A. Yingst ${ }^{\mathrm{f}}$, S.C. Mest $^{\mathrm{f}}{ }^{\text {, C.T. Russell }}{ }^{\mathrm{g}}$, C.A. Raymond ${ }^{\mathrm{h}}$
}

\author{
${ }^{a}$ Institute of Geological Sciences, Freie Universitaet Berlin, 12249 Berlin, Germany \\ b Max Planck Institute for Solar System Research, 37077 Göttingen, Germany \\ 'School of Earth and Space Exploration, Arizona State University, Tempe, AZ 85287, USA \\ ${ }^{\mathrm{d}}$ German Aerospace Center (DLR), 12489 Berlin, Germany \\ e John Hopkins University Applied Physics Laboratory, Laurel, MD 20723, USA \\ ${ }^{\mathrm{f}}$ Planetary Science Institute, Tucson, AZ 85719, USA \\ ${ }^{\mathrm{g}}$ Institute of Geophysics and Planetary Physics, University of California, Los Angeles, CA 90095, USA \\ ${ }^{\mathrm{h}}$ Jet Propulsion Laboratory, California Institute of Technology, Pasadena, CA 91109, USA
}

\section{A R T I C L E I N F O}

\section{Article history:}

Received 16 May 2013

Revised 5 February 2014

Accepted 9 February 2014

Available online $\mathrm{xxxx}$

\section{Keywords:}

Asteroid Vesta

Asteroids, surfaces

Cratering

Geological processes

Impact processes

\begin{abstract}
A B S T R A C T
A variety of geologic landforms and features are observed within quadrangle Av-13 Tuccia in the southern hemisphere of Vesta. The quadrangle covers parts of the highland Vestalia Terra as well as the floors of the large Rheasilvia and Veneneia impact basins, which results in a substantial elevation difference of more than $40 \mathrm{~km}$ between the northern and the southern portions of the quadrangle. Measurements of crater size-frequency distributions within and surrounding the Rheasilvia basin indicate that gravity-driven mass wasting in the interior of the basin has been important, and that the basin has a more ancient formation age than would be expected from the crater density on the basin floor alone. Subsequent to its formation, Rheasilvia was superimposed by several mid-sized impact craters. The most prominent craters are Tuccia, Eusebia, Vibidia, Galeria, and Antonia, whose geology and formation ages are investigated in detail in this work. These impact structures provide a variety of morphologies indicating different sorts of subsequent impact-related or gravity-driven mass wasting processes. Understanding the geologic history of the relatively young craters in the Rheasilvia basin is important in order to understand the even more degraded craters in other regions of Vesta.
\end{abstract}

(c) 2014 Elsevier Inc. All rights reserved.

\section{Introduction and general geologic setting of quadrangle Av-13}

The investigation of the main belt Asteroid 4 Vesta by NASA's Dawn mission (Russell et al., 2012) includes an extensive geologic mapping program. Besides a global geologic map at a scale of 1:500,000 (Yingst et al., 2013) this mapping program consists of the production of 15 geological quadrangle maps at a scale of 1:250,000 (Roatsch et al., 2012; Williams et al., this issue-b).

The quadrangle Av-13 called Tuccia covers the region between $21-66^{\circ} \mathrm{S}$ latitude and $180-270^{\circ} \mathrm{E}$ longitude. The quadrangle represents the transition zone between the topographically

* Corresponding author. Address: Institute of Geological Sciences, Planetary Sciences and Remote Sensing, Freie Universitaet Berlin, Malteserstr. 74-100, 12249 Berlin, Germany. Fax: +4930838 70723 .

E-mail address: Thomas.Kneissl@fu-berlin.de (T. Kneissl). elevated Vestalia Terra and the floor of the Rheasilvia basin (see Fig. 1). The Rheasilvia impact structure, whose existence has already been suggested by e.g., Thomas et al. (1997) and Binzel et al. (1997) using data from the Hubble Space Telescope (HST), is centered close to the south pole of Vesta at $\sim 75^{\circ} \mathrm{S}, \sim 301^{\circ} \mathrm{E}$ and is approximately $500 \pm 20 \mathrm{~km}$ in diameter (e.g., Jaumann et al., 2012b; Schenk et al., 2012a). Measuring the crater size-frequency distribution (CSFD) on the relatively lightly-cratered basin floor of Rheasilvia, Marchi et al. (2012) determined a formation time of approximately $1 \mathrm{Ga}$ ago, although this has been questioned by Schmedemann et al. (2012b). Undetected by the HST, Rheasilvia superposes a second large basin with almost the same diameter, which has been named Veneneia. This basin has a diameter of $\sim 400 \pm 20 \mathrm{~km}$ and its center is located at $\sim 52^{\circ} \mathrm{S}$ and $\sim 170^{\circ} \mathrm{E}$ (e.g., Jaumann et al., 2012b; Schenk et al., 2012a). Portions of the floors of both impact structures are located within the Tuccia quadrangle. 
While the Veneneia floor covers only the north-western edge of the quadrangle, Rheasilvia approximately constitutes the southern half of the quadrangle. The exact boundaries of the original basin rims are difficult to determine as they are heavily degraded and modified by landslides and slope slumping, particularly at the southern scarp of Vestalia Terra (see Fig. 1).

Vestalia Terra is a high elevation plateau mainly located in the equatorial mapping quadrangle Numisia (Av-9, Yingst et al., 2013; Buczkowski et al., this issue). The southern edge of Vestalia Terra extends into the Tuccia quadrangle. Here, Vestalia Terra reaches a maximum height of approximately $19.6 \mathrm{~km}$ above the Vesta ellipsoid. In combination with the depth of the Rheasilvia basin - of more than $22.4 \mathrm{~km}$ in the south-eastern region of the quadrangle - this results in topographic variation exceeding $40 \mathrm{~km}$ leading to widespread mass wasting processes such as landslides and slumps, throughout the quadrangle. This complex geologic setting that extends over large parts of the southern hemisphere of Vesta was subsequently modified by mid-sized impact events. In contrast to craters on the heavily-cratered terrains in the northern hemisphere of Vesta (Marchi et al., 2012; Hiesinger et al., 2013), craters on the more lightly cratered floor of Rheasilvia show distinct stratigraphic relationships and, thus, allow for relatively unambiguous analyses of crater morphologies and relative formation ages. The prominent impact craters in quadrangle Av13, named Eusebia, Tuccia, Vibidia, Galeria, and Antonia (see Fig. 1), offer a rich variety of impact morphologies, erosion types, as well as exposures of dark and bright materials (Kneissl et al., 2013) and, thus, these craters are appropriate candidates to investigate young, mid-sized impact morphologies on Vesta's surface.

\section{Methodology}

\subsection{Database and geologic mapping}

Quadrangle Av-13 Tuccia is one of 15 mapping quadrangles of Vesta, with two at the poles, four in the mid-latitude regions, respectively, and five in the equatorial region (Roatsch et al.,
2012, see Fig. 2). The presented map (Fig. 3 and SOM) uses the 'Claudia' coordinate system, which is different from the coordinate system used to publish data in Planetary Data System (Li, 2012) that follows IAU coordinate system recommendations (Archinal et al., 2011). Positive longitudes here are offset by 150 degrees from the 'IAU/PDS' system, in the sense that Claudia longitude $=$ IAU longitude $-150^{\circ}$ (for details see the Coordinate system section in Williams et al., this issue-b).

The geologic mapping was based on a mosaic of Framing Camera (FC) clear-filter imagery derived during the Low Altitude Mapping Orbit (LAMO) of the Dawn spacecraft (Russell and Raymond, 2011; Sierks et al., 2011) (Fig. 2A). The mosaic provided a spatial resolution of $20 \mathrm{~m} / \mathrm{px}$. Small gaps in the north-eastern part of the quadrangle were filled with image data from the High Altitude Mapping Orbit (HAMO) with a resolution of $70 \mathrm{~m} / \mathrm{px}$ (Roatsch et al., 2012). Single LAMO FC clear-filter images with native resolution ( $>15 \mathrm{~m} / \mathrm{px})$ were processed with the USGS Integrated Software for Imagers and Spectrometers (ISIS) (Becker et al., 2012) and used for detailed investigations. Since the albedo of a surface unit is an important property for geologic mapping, we also made use of a mosaic of photometrically corrected FC clear-filter images $(70 \mathrm{~m} /$ px) obtained during the HAMO mapping phase and provided by the DAWN Team. Multispectral data that was derived from Framing Camera (FC) color filter images (Sierks et al., 2011) was used to map unit boundaries of ejecta blankets and dark material occurrences. Here, we applied Clementine-like color ratio maps (hereafter called color ratio maps) with a resolution of $70 \mathrm{~m} / \mathrm{px}$ (Fig. 2C). In these composite color maps the red channel is the ratio of $750 /$ $440 \mathrm{~nm}$ filters, green is $750 / 920 \mathrm{~nm}$ filter ratio and blue is the ratio of 440/750 nm filters (e.g., Le Corre et al., 2011, 2012b; Nathues et al., 2012; Reddy et al., 2012a, 2012b). The red channel shows a steeper visible spectral slope, the green channel is a function of mafic mineral absorption band depth (an indicator for iron abundance, particle size effects, space weathering), and the blue channel is the inverse of the red channel helping to constrain weaker spectral slopes than the average surface (Reddy et al., 2012a, 2012b).

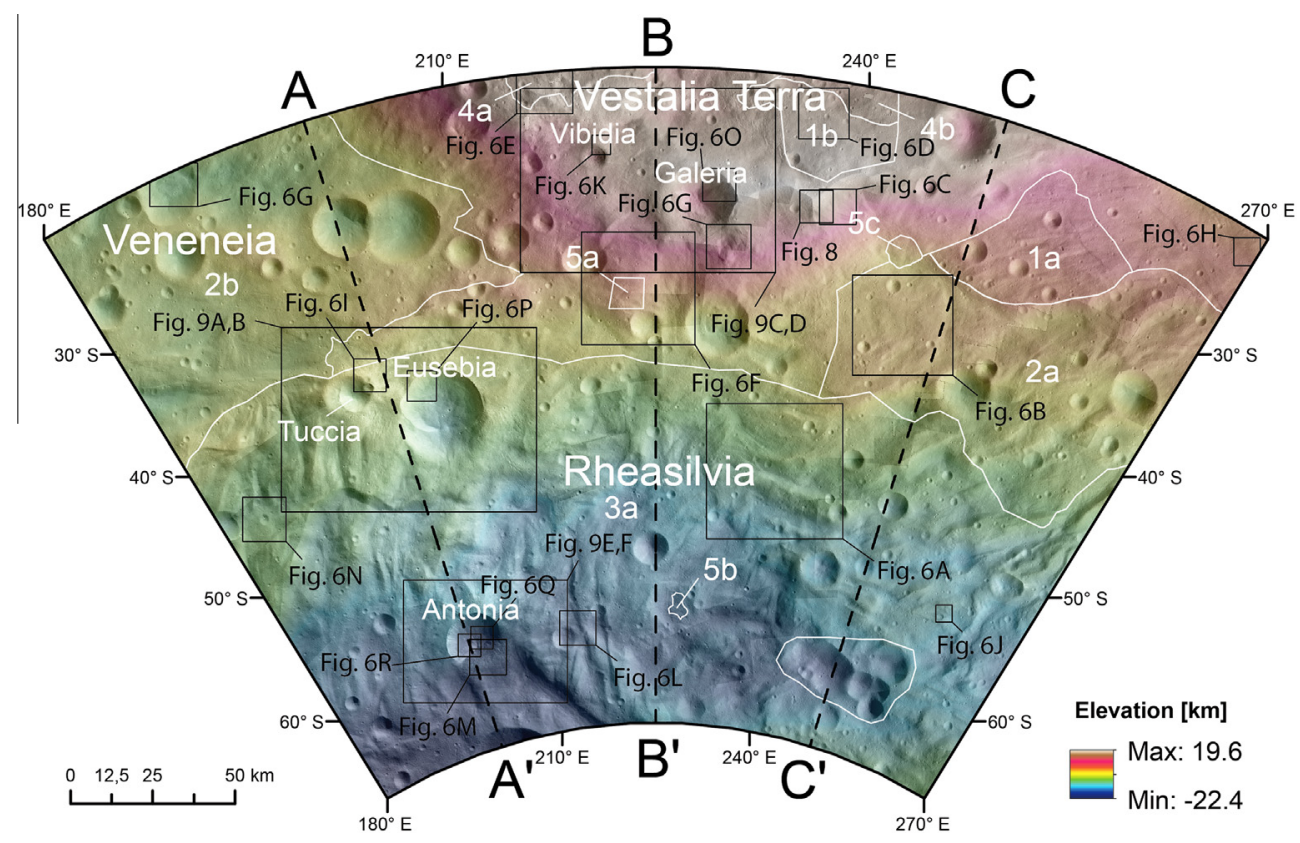

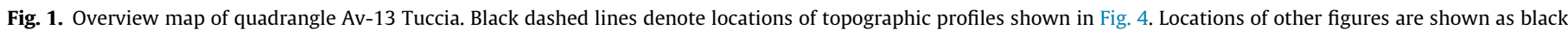

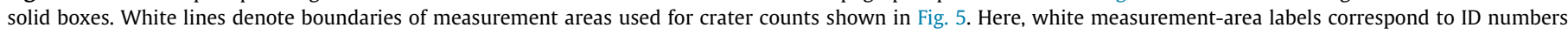

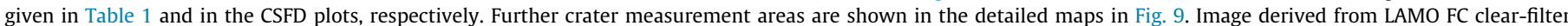

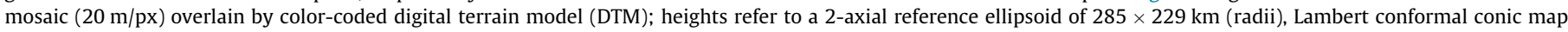
projection with central meridian at $225^{\circ} \mathrm{E}$ and standard parallels at $30^{\circ} \mathrm{S}$ and $58^{\circ} \mathrm{S}$. 


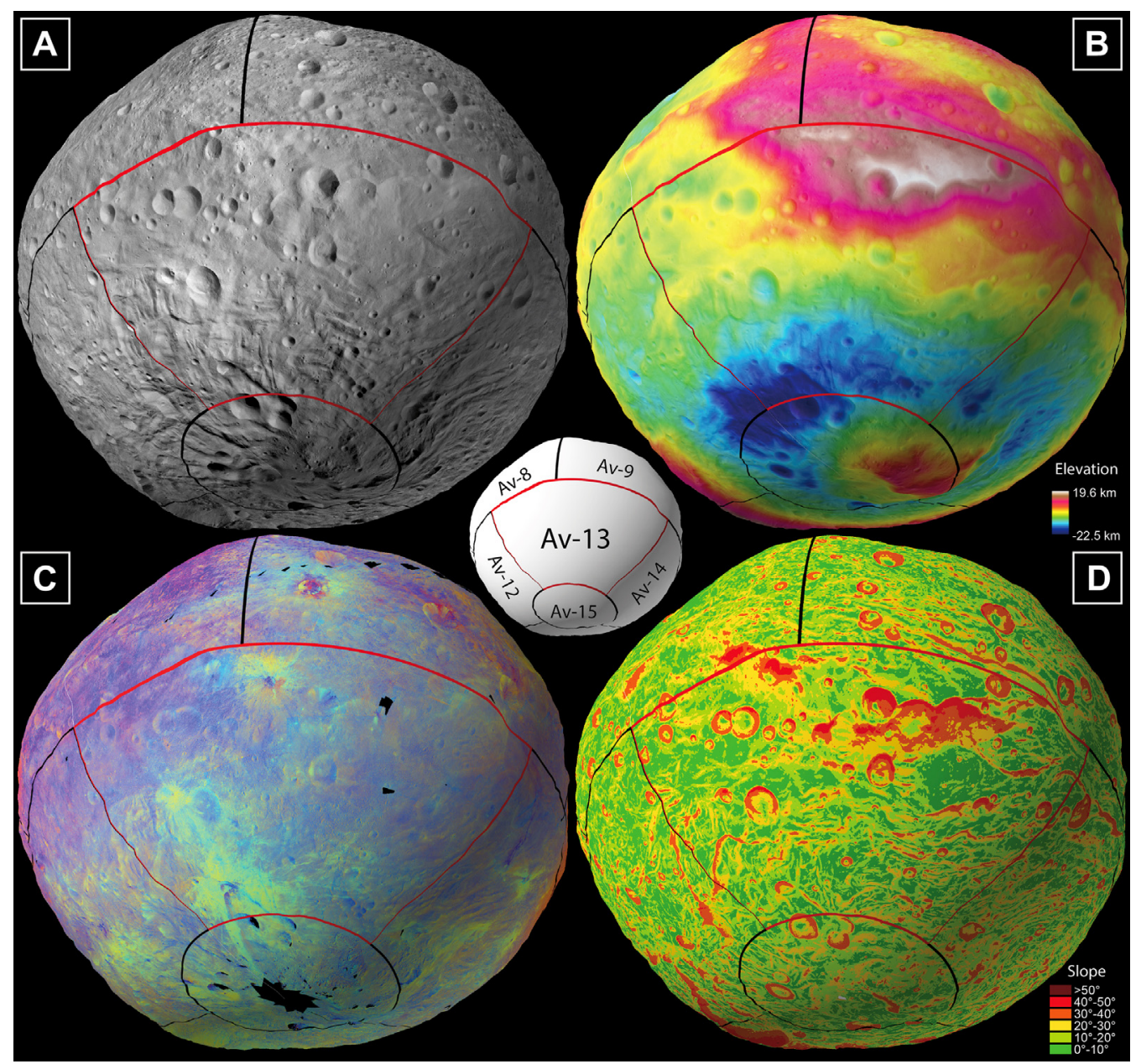

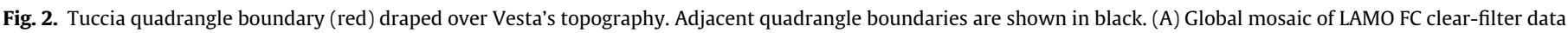
$(20 \mathrm{~m} / \mathrm{px})$. LAMO coverage gaps were filled with HAMO FC data. (B) Color-coded digital terrain model (DTM) $(92 \mathrm{~m} / \mathrm{px})$. Heights refer to a 2-axial reference ellipsoid of $285 \times 229 \mathrm{~km}$ (radii). (C) Clementine-type color ratio map (70 m/px) derived from FC color data (red 750/440 nm; green 750/920 nm; blue 440/750 nm). (D) Slope map $(92 \mathrm{~m} / \mathrm{px})$ derived from the ellipsoid-based DTM described above. Slope values were calculated in a conformal Mercator map projection and corrected for scale errors subsequently.

Topographic analyses, e.g., the creation of slope maps and topographic profiles (e.g., Fig. 4), were carried out using a digital terrain model (DTM) derived from stereo imagery (Preusker et al., 2012a) (Fig. 2B). The lateral resolution of the DTM amounts to $92 \mathrm{~m} / \mathrm{px}$ and the three-dimensional point accuracy is $\pm 8 \mathrm{~m}$ (Preusker et al., $2012 \mathrm{~b}, 2012 \mathrm{c})$. The reference body is an ellipsoid of $285 \times$ $285 \times 229 \mathrm{~km}$ (radii). The slope map (Fig. 2D) was particularly useful for distinguishing between troughs, scarps, and grooves. Further information on the Dawn data products used for geologic mapping of Vesta can be found in the introductory paper of the Special Issue on the Geologic Mapping of Vesta (Williams et al., this issue-b).

The final map uses a Lambert conformal conic map projection with standard parallels at $30^{\circ} \mathrm{S}$ and $58^{\circ} \mathrm{S}$ and a central meridian at $225^{\circ} \mathrm{E}$ at the scale of $1: 250,000$ (Roatsch et al., 2012). This map is in agreement with the symbolization used for the global geologic map of Vesta (Yingst et al., 2013). Here, we used map units and symbols according to the Digital Cartographic Standard for Geologic Map Symbolization (U.S.G.S., 2006) realized for usage in ESRI's ArcGIS by Nass et al. (2011).

\subsection{Analysis of crater size-frequency distributions (CSFDs)}

\subsubsection{Measurements of CSFDs}

In order to consider the stratigraphy of the mapped geological units, or rather for the determination of relative and absolute surface ages, we measured CSFDs on the unit surfaces. Here, the minimum crater diameter used for these analyses depended on the unit size. On large-scale units, e.g., on Rheasilvia ridge-andgroove material (unit Rrg) or the cratered plains material (unit $\mathrm{cp}$ ), we measured craters down to one kilometer in diameter. On smaller geologic units, such as on the ejecta blankets of Vibidia or Antonia or on landslide and slump deposits, we used individual LAMO images with native resolution $(>15 \mathrm{~m} / \mathrm{px})$ in order to measure crater diameters down to the image-resolution limit, i.e. $\sim 60-70 \mathrm{~m}$. Craters were mapped using the CraterTools extension for ESRI's ArcGIS described in Kneissl et al. (2011). This software helps to avoid errors of crater diameters and measurement area sizes related to map-projection induced distortions. However, due to the large deviations (up to $30 \mathrm{~km}$ ) of the actual surface from the reference body used for the map projection (sphere with a radius of $255 \mathrm{~km}$ ), these values can differ from the true distances and area sizes on the actual surface. All the CSFD measurements were corrected for these elevation-induced distortions. The true diameter can be calculated using:

$D_{u}=\frac{D_{d}}{r} \times(r+E)$

where $D_{u}$ is the undistorted crater diameter, $D_{d}$ the distorted diameter, $r$ the radius of the reference body, and $E$ the elevation above 


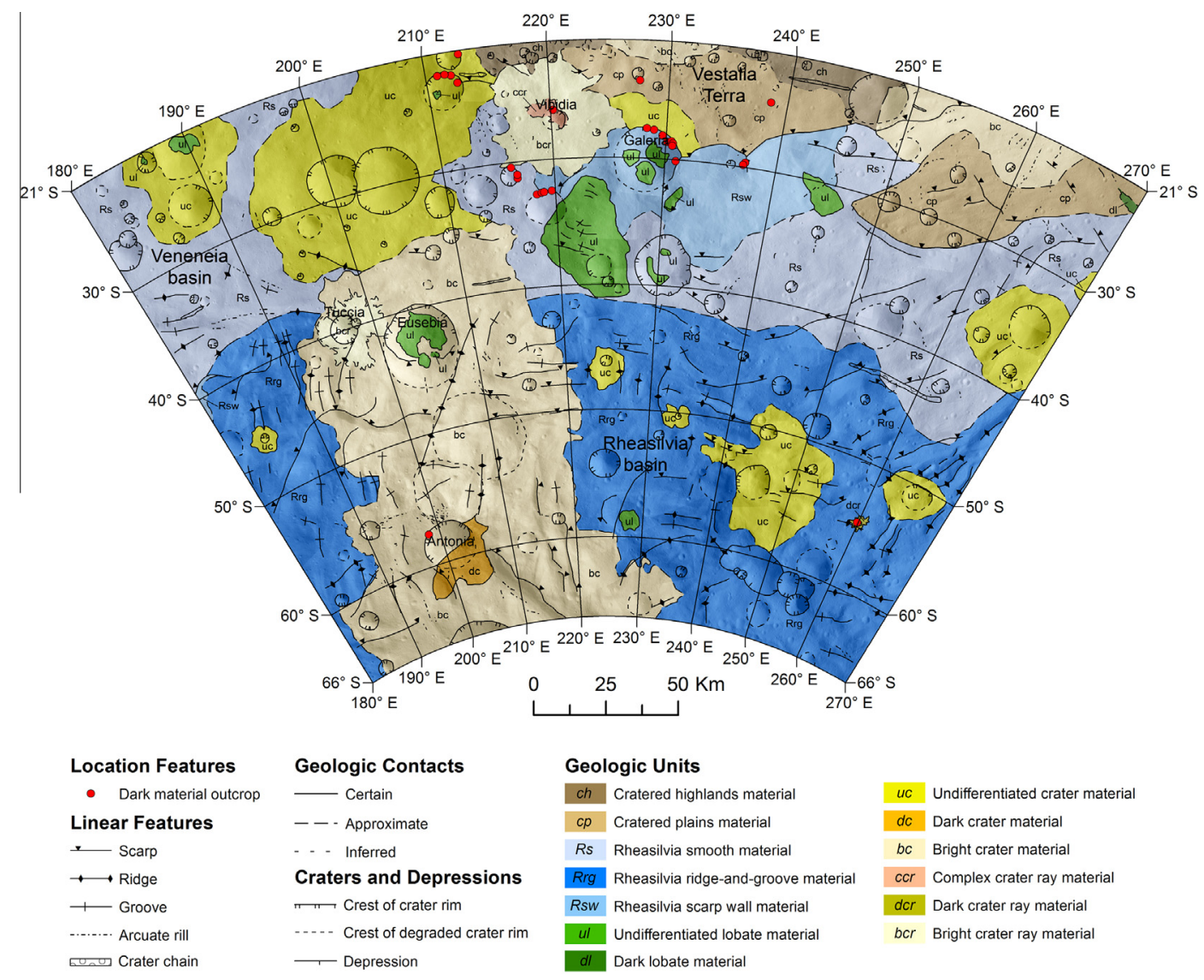

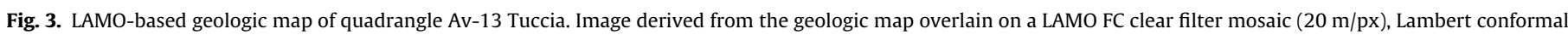

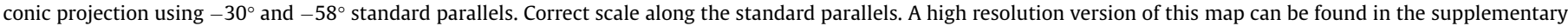
online material.
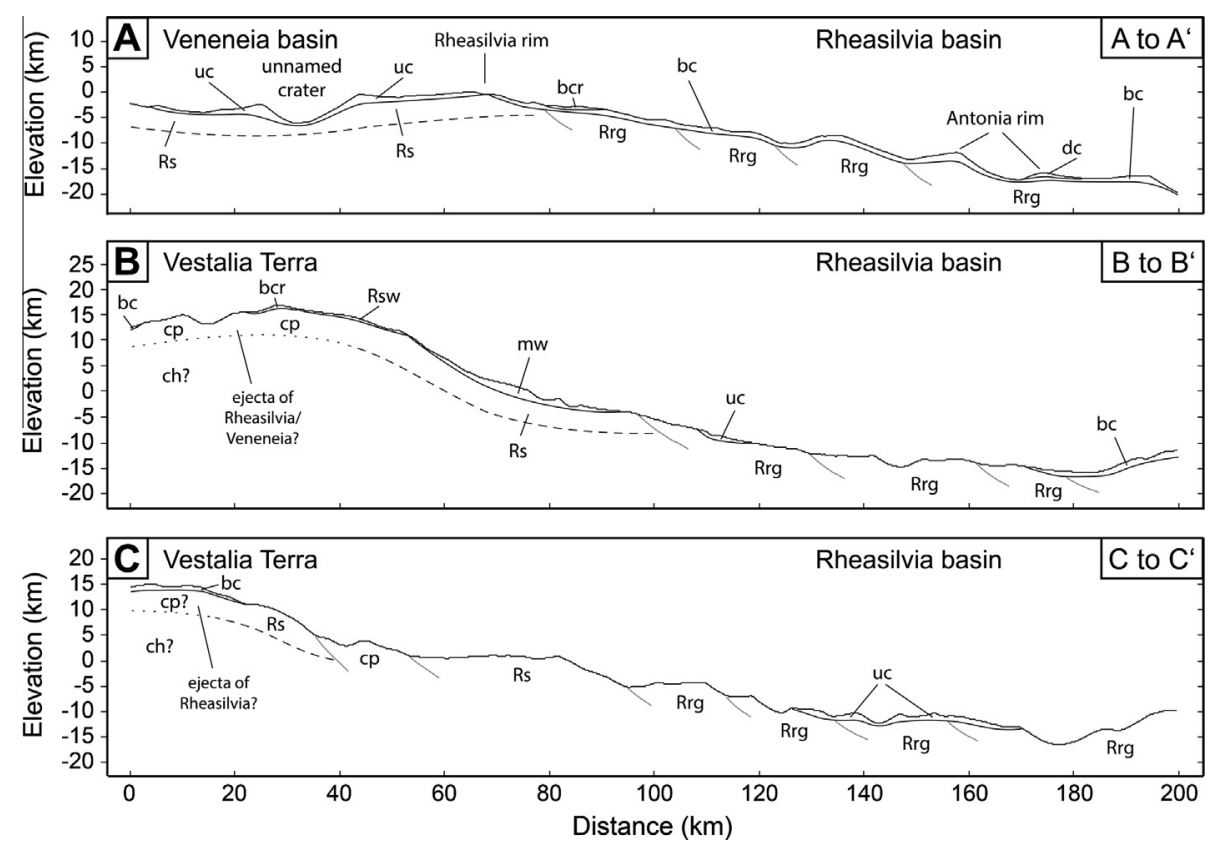

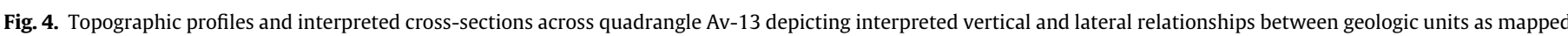

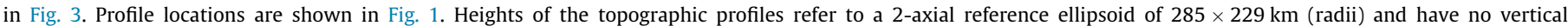
exaggeration. 
the reference body. For the calculation of true area sizes the following formula was used:

$A_{u}=\left(\frac{\sqrt{A_{d}}}{r} \times(r+E)\right)^{2}$

where $A_{u}$ is the undistorted area size and $A_{d}$ the distorted area size.

To gain a better overview of all CSFD analyses carried out in this work we assigned a unique identification number (ID) to each CSFD measurement. This ID was used for measurement-area locations in the overview maps, for the CSFD plots, as well as for the measurement details given in Table 1 .

\subsubsection{Deriving cratering model ages}

The CSF data was plotted and analyzed with the CraterStats software (Michael and Neukum, 2010; Michael, 2013). Here, cratering model ages are obtained by fitting a given production function (PF) to the observed CSFD using a non-linear least-squares fitting procedure. As a result the PF provides a theoretical equivalent $N(1)$ value which can be used to obtain a cratering model age from the chronology function (CF).

Errors given for the crater model ages in the CSF plots, in Table 1, and in the text refer solely to the stochastic uncertainty of the individual CSF measurements. Here, the error bars of the individual crater bins in the CSF plots represent one standard deviation, $\sigma$, for each data point (Arvidson, 1979). The magnitude of uncertainties given for the individual cratering model ages depend on the number of craters in the fitted diameter range and arise from the statistics of the Poisson cratering process in combination with the non-linear CF (Michael and Neukum, 2010). It should be emphasized that the given errors do not relate to any systematic error in the determination or calibration of the applied chronology function and production functions. Thus, one should be cautious not to over-interpret the absolute model-ages and their corresponding errors. However, when a CSFD runs parallel to the PF and provides sufficient crater statistics, our method provides reliable results for the analysis of relative age differences, especially when craters in the same diameter range are used.

In this work we made use of two different combinations of $\mathrm{CF}$ and PF. The first combination consists of the lunar-like CF and PF scaled to Vestan impact conditions (revision 3) provided in Schmedemann et al. (2012a, submitted for publication). The second combination is the $\mathrm{CF}$ based on dynamical models of the asteroid belt including the Late Heavy Bombardment (LHB) scenario (O’Brien et al., 2012, submitted for publication; O’Brien, 2013) with the PF based on the size-frequency distribution of the Main-Belt Asteroids (MBA) derived by Marchi (Marchi et al., 2013; O’Brien, 2013). Since the two CFs are nearly identical over the time range from the present back to $3 \mathrm{Ga}$ ago, age differences derived from CSFDs on younger surfaces are mainly a result of the different shapes of the given PFs. For details and background explanations for both systems please see the respective publications and references therein.

During data analysis we found that, especially in the smalldiameter range, the PF by Marchi et al. is often too shallow in order to fit the measured CSFDs. This is in contrast to the PF by Schmedemann et al. which is steeper in the small diameter-range and produces better fits to young/fresh, undisturbed CSFDs. In this respect, it is important to note that only undisturbed (commonly the steepest) CSFDs in a region provide information about the shape of the PF. Shallower CSFDs are often the result of subsequent obliteration of small-diameter craters by erosive or mantling processes, such as the emplacement of an ejecta blanket (see detailed explanation in the next section). We should note that a PF is always an averaged CSFD, which might vary slightly with time (Schmedemann et al., submitted for publication). However, we generally found a very good agreement between the measured steep CSFDs in the Tuccia quadrangle and the PF by Schmedemann et al. This also includes several CSFDs measured on older surface units containing largerdiameter craters, e.g., in the interior of Rheasilvia. Due to the better fit of the PF by Schmedemann et al. to the obtained CSFDs, we decided to use the ages derived with the chronology system by Schmedemann et al. (2012a, submitted for publication) in the data plots and the text presented in this work. Nevertheless, all CSF measurements have additionally been fitted and analyzed using the functions by O'Brien et al. and Marchi et al. The resulting ages of both approaches are presented in Table 1 .

\subsubsection{Resurfacing processes}

Besides the CSFD curves that are in good agreement with the proposed PF there are several CSFD measurements in this work showing distinct kinks and flat portions of the curves. One possible explanation might be a slightly time-variable PF that might lead to different shapes of CSFDs on differently aged surfaces. However, the flat portions of some of these measurements are cut by other CSFDs that follow the given PF (e.g., the flat portion of measurement ID 8b is cut by the steeper CSFD of measurement ID 9a). Such an overlap cannot be explained by a time-variable PF because an undisturbed older CSFD always has to contain a higher crater frequency over the complete diameter range than a younger CSFD. Thus, it is implausible that time-dependent variations of the PF are responsible for all of the observed kinks and flattenings of the CSF curves.

A more plausible explanation for the shapes of the CSF curves is the influence of geologic processes that are able to erode or mantle impact craters. Typically, these (partial) resurfacing processes obliterate smaller craters from the distribution before larger impact craters are affected (e.g., Hartmann, 1971; Neukum and Horn, 1976; Hartmann and Werner, 2010). The consequences are characteristic "kinks" in the observed CSFDs and multiple portions of the curve consistent with (i.e., parallel to) the PF. These multiple segments of the CSFD can be used for age extractions, respectively (e.g., Neukum and Hiller, 1981; Werner, 2005; Michael and Neukum, 2010). Here, the large-diameter portion of the curve, i.e., the craters not affected by the resurfacing process, provides information about the age of the original surface. In the case of an emplacement of a thin lava flow or an ejecta blanket this is the age of the underlying surface, defined by the large craters still visible through the lava/ejecta. The small-diameter part of the CSFD curve, i.e., the craters formed after the resurfacing process ended, defines the age of the end of the resurfacing process, e.g., the age of the emplacement of the lava flow or the ejecta blanket (e.g., Hiesinger et al., 2002). The signature in the CSFD does however not always reveal whether this process was a single discrete resurfacing event with a specific age, multiple events with a similar intensity, or if the flattened portion of the CSFD reflects an ongoing erasure of craters over a long period of time (Michael and Neukum, 2010; Michael, 2013). However, most CSFD measurements in this study showing distinct resurfacing signatures are located next to impact structures. Here, the emplacement of an ejecta blanket and/or the degradation by impact-induced seismic shaking (e.g., Titley, 1966; Richardson et al., 2005; Thomas and Robinson, 2005) very likely acts as a discrete, short-lived resurfacing event. This is often confirmed by the morphology of the large-diameter craters that show mantling by the ejecta blankets. In order to create a resurfacing signature with a second steep portion of the CSFD, a long-lasting process of craters degradation would have to stop abruptly. If not, craters could not re-accumulate on the surface showing the same slope as the production function. On Vesta an abrupt end of such a long-lasting, crater-eroding process is hard to explain. Ejecta emplacement however is a discrete resurfacing event with a specific age giving a plausible explanation for the 


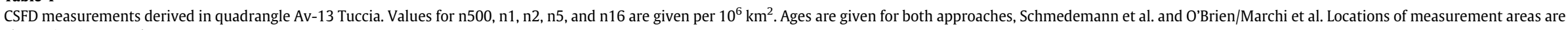
shown in Figs. 1 and 9.

\begin{tabular}{|c|c|c|c|c|c|c|c|c|c|c|c|c|c|c|c|c|c|c|c|c|c|c|c|}
\hline \multirow[t]{2}{*}{ ID } & \multirow{2}{*}{$\begin{array}{l}\text { Measurement } \\
\text { name }\end{array}$} & \multirow{2}{*}{$\begin{array}{l}\text { Area } \\
\left(\mathrm{km}^{2}\right)\end{array}$} & \multirow{2}{*}{$\begin{array}{l}\mathrm{n} \\
\text { cum }\end{array}$} & \multirow[t]{2}{*}{ n500 } & \multirow[t]{2}{*}{$\mathrm{n} 1$} & \multirow[t]{2}{*}{ n2 } & \multirow[t]{2}{*}{ n5 } & \multirow[t]{2}{*}{ n16 } & \multirow{2}{*}{$\begin{array}{l}\text { Age } \\
\text { type }\end{array}$} & \multicolumn{7}{|c|}{ Schmedemann et al. } & \multicolumn{7}{|c|}{ O'Brien et al./Marchi et al. } \\
\hline & & & & & & & & & & $\begin{array}{l}\text { Age } \\
(\mathrm{Ga})\end{array}$ & $\begin{array}{l}\text { Error } \\
\text { up (Ga) }\end{array}$ & $\begin{array}{l}\text { Error } \\
\text { down } \\
\text { (Ga) }\end{array}$ & $\begin{array}{l}\mathrm{n} \\
\text { fit }\end{array}$ & $\mathrm{n} 1$ fit & $\begin{array}{l}D \\
\min \\
\text { fit } \\
(\mathrm{km}) \\
\end{array}$ & $\begin{array}{l}D \\
\max \\
\text { fit } \\
(\mathrm{km}) \\
\end{array}$ & $\begin{array}{l}\text { Age } \\
(\mathrm{Ga})\end{array}$ & $\begin{array}{l}\text { Error } \\
\text { up } \\
\text { (Ga) }\end{array}$ & $\begin{array}{l}\text { Error } \\
\text { down } \\
\text { (Ga) }\end{array}$ & $\begin{array}{l}\mathrm{n} \\
\text { fit }\end{array}$ & $\mathrm{n} 1 \mathrm{fit}$ & $\begin{array}{l}D \\
\min \\
\text { fit } \\
(\mathrm{km}) \\
\end{array}$ & $\begin{array}{l}D \\
\max \\
\text { fit } \\
(\mathrm{km}) \\
\end{array}$ \\
\hline 1a & Cratered & 1604 & 49 & 30,550 & 24,310 & 4988 & 2494 & 0 & Base & 3.41 & 0.15 & 1.1 & 4 & 0.0932 & 4.5 & 9 & 2.116 & 0.988 & 1.032 & 4 & 0.0434 & 4.5 & 9 \\
\hline & $\begin{array}{l}\text { Plains } \\
\text { Material } 1\end{array}$ & & & & & & & & Resurf & 1.13 & 0.17 & 0.17 & 36 & 0.0231 & 0.9 & 2 & 0.720 & 0.189 & 0.190 & 10 & 0.0145 & 1.4 & 3 \\
\hline $1 \mathrm{~b}$ & $\begin{array}{l}\text { Cratered } \\
\text { Plains } \\
\text { Material } 2\end{array}$ & 969.6 & 62 & 63,940 & 25,780 & 7219 & 0 & 0 & Base & 2.99 & 0.37 & 1.1 & 7 & 0.0622 & 2 & 4.5 & 1.602 & 0.344 & 0.348 & 20 & 0.0326 & 1.2 & 4.5 \\
\hline $2 a$ & $\begin{array}{l}\text { Rheasilvia } \\
\text { Smooth } \\
\text { Material East }\end{array}$ & 6079 & 99 & 16,290 & 14,480 & 4770 & 987 & 164.5 & Base & 2.47 & 0.55 & 0.63 & 14 & 0.0504 & 3 & 17 & 1.064 & 0.126 & 0.126 & 68 & 0.0215 & 1.3 & 20 \\
\hline $2 \mathrm{~b}$ & $\begin{array}{l}\text { Rheasilvia } \\
\text { Smooth } \\
\text { Material West }\end{array}$ & 8024 & 119 & 14,830 & 12,340 & 4860 & 1371 & 498.5 & $\begin{array}{l}\text { Base } \\
\text { Resurf }\end{array}$ & $\begin{array}{l}3.46 \\
1.72\end{array}$ & $\begin{array}{l}0.09 \\
0.27\end{array}$ & $\begin{array}{l}0.22 \\
0.27\end{array}$ & $\begin{array}{l}11 \\
28\end{array}$ & $\begin{array}{l}0.105 \\
0.035\end{array}$ & $\begin{array}{l}6 \\
2\end{array}$ & $\begin{array}{l}25 \\
5\end{array}$ & $\begin{array}{l}3.819 \\
1.039\end{array}$ & $\begin{array}{l}0.509 \\
0.162\end{array}$ & $\begin{array}{l}1.320 \\
0.163\end{array}$ & $\begin{array}{l}7 \\
28\end{array}$ & $\begin{array}{l}0.0825 \\
0.021\end{array}$ & $\begin{array}{l}11 \\
2\end{array}$ & $\begin{array}{l}25 \\
5\end{array}$ \\
\hline $3 a$ & $\begin{array}{l}\text { Rheasilvia } \\
\text { Ridge and } \\
\text { Groove } \\
\text { Material }\end{array}$ & 21,700 & 392 & 18,060 & 14,380 & 4838 & 1198 & 184.3 & Base & 2.31 & 0.32 & 0.32 & 51 & 0.047 & 3 & 35 & 1.122 & 0.128 & 0.129 & 73 & 0.0227 & 2.5 & 35 \\
\hline $4 a$ & $\begin{array}{l}\text { Cratered } \\
\text { Highlands } \\
\text { Material } 1\end{array}$ & 315.4 & 25 & 87,250 & 60,690 & 18,970 & 0 & 0 & Base & 3.67 & 0.051 & 0.08 & 12 & 0.217 & 1.7 & 5 & 4.428 & 0.051 & 0.414 & 12 & 0.126 & 1.7 & 5 \\
\hline $4 \mathrm{~b}$ & $\begin{array}{l}\text { Cratered } \\
\text { Highlands } \\
\text { Material } 2\end{array}$ & 263.6 & 25 & 87,250 & 60,690 & 18,970 & 0 & 0 & Base & 3.53 & 0.073 & 0.14 & 11 & 0.128 & 1.4 & 3.5 & 3.881 & 0.367 & 0.903 & 14 & 0.0845 & 1.2 & 3.5 \\
\hline $5 a$ & $\begin{array}{l}\text { Lobate } \\
\text { material } 1\end{array}$ & 103 & 437 & 67,950 & 0 & 0 & 0 & 0 & Base & 0.332 & 0.046 & 0.047 & 50 & 0.00677 & 0.25 & 1 & 0.706 & 0.038 & 0.038 & 332 & 0.0142 & 0.11 & 1 \\
\hline $5 b$ & $\begin{array}{l}\text { Lobate } \\
\text { material } 2\end{array}$ & 21.21 & 124 & 0 & 0 & 0 & 0 & 0 & Base & 0.15 & 0.028 & 0.028 & 28 & 0.00305 & 0.14 & 0.45 & 0.478 & 0.065 & 0.065 & 52 & 0.00959 & 0.1 & 0.45 \\
\hline $5 c$ & $\begin{array}{l}\text { Lobate } \\
\text { material } 3\end{array}$ & 83.38 & 194 & 23,990 & 0 & 0 & 0 & 0 & Base & 0.0925 & 0.01 & 0.01 & 78 & 0.00188 & 0.14 & 0.45 & 0.346 & 0.026 & 0.026 & 175 & 0.00693 & 0.1 & 0.8 \\
\hline $6 a$ & Tuccia Ejecta & 30.61 & 306 & 294,000 & 32,670 & 0 & 0 & 0 & Base & 2.08 & 0.67 & 0.69 & 9 & 0.0424 & 0.5 & 1.1 & 2.651 & 0.676 & 0.706 & 13 & 0.0549 & 0.4 & 1.1 \\
\hline & North-West & & & & & & & & Resurf & 0.17 & 0.015 & 0.015 & 108 & 0.00346 & 0.11 & 0.35 & 0.730 & 0.055 & 0.055 & 159 & 0.0147 & 0.09 & 0.35 \\
\hline $6 \mathrm{~b}$ & $\begin{array}{l}\text { Tuccia Ejecta } \\
\text { South-West }\end{array}$ & 160.8 & 636 & 74,610 & 37,310 & 18,650 & 0 & 0 & $\begin{array}{l}\text { Base } \\
\text { Resurf }\end{array}$ & $\begin{array}{l}3.5 \\
0.174\end{array}$ & $\begin{array}{l}0.1 \\
0.0083\end{array}$ & $\begin{array}{l}0.34 \\
0.0083\end{array}$ & $\begin{array}{l}6 \\
412\end{array}$ & $\begin{array}{l}0.115 \\
0.00355\end{array}$ & $\begin{array}{l}1.3 \\
0.12\end{array}$ & $\begin{array}{l}4.5 \\
0.4\end{array}$ & $\begin{array}{l}3.658 \\
0.691\end{array}$ & $\begin{array}{l}0.622 \\
0.030\end{array}$ & $\begin{array}{l}1.397 \\
0.030\end{array}$ & $\begin{array}{l}6 \\
488\end{array}$ & $\begin{array}{l}0.078 \\
0.0139\end{array}$ & $\begin{array}{l}1.3 \\
0.11\end{array}$ & $\begin{array}{l}4.5 \\
0.6\end{array}$ \\
\hline $6 c$ & $\begin{array}{l}\text { Tuccia Bright } \\
\text { Rayed Crater }\end{array}$ & 75.44 & 524 & 159,100 & 39,770 & 26,510 & 0 & 0 & $\begin{array}{l}\text { Base } \\
\text { Resurf }\end{array}$ & $\begin{array}{l}3.62 \\
0.764\end{array}$ & $\begin{array}{l}0.11 \\
0.2\end{array}$ & $\begin{array}{l}1 \\
0.2\end{array}$ & $\begin{array}{l}2 \\
11\end{array}$ & $\begin{array}{l}0.177 \\
0.0156\end{array}$ & $\begin{array}{l}1.7 \\
0.45\end{array}$ & $\begin{array}{l}3 \\
0.8\end{array}$ & $\begin{array}{l}4.199 \\
1.375\end{array}$ & $\begin{array}{l}0.288 \\
0.333\end{array}$ & $\begin{array}{l}2.670 \\
0.336\end{array}$ & $\begin{array}{l}2 \\
13\end{array}$ & $\begin{array}{l}0.103 \\
0.0279\end{array}$ & $\begin{array}{l}1.7 \\
0.4\end{array}$ & $\begin{array}{l}3 \\
0.9\end{array}$ \\
\hline & & & & & & & & & Resurf & 0.16 & 0.011 & 0.011 & 178 & 0.00326 & 0.12 & 0.25 & 0.617 & 0.029 & 0.029 & 423 & 0.0124 & 0.08 & 0.3 \\
\hline $6 \mathrm{~d}$ & $\begin{array}{l}\text { Tuccia Rim } \\
\text { Transition } \\
\text { North }\end{array}$ & 23.57 & 110 & 127,300 & 0 & 0 & 0 & 0 & $\begin{array}{l}\text { Base } \\
\text { Resurf }\end{array}$ & $\begin{array}{l}0.701 \\
0.162\end{array}$ & $\begin{array}{l}0.4 \\
0.02\end{array}$ & $\begin{array}{l}0.4 \\
0.02\end{array}$ & $\begin{array}{l}3 \\
57\end{array}$ & $\begin{array}{l}0.0143 \\
0.00329\end{array}$ & $\begin{array}{l}0.45 \\
0.12\end{array}$ & $\begin{array}{l}0.8 \\
0.3\end{array}$ & 0.775 & 0.103 & 0.103 & 55 & 0.0156 & 0.13 & 0.8 \\
\hline 6e & $\begin{array}{l}\text { Tuccia Rim } \\
\text { Transition } \\
\text { South }\end{array}$ & 17.36 & 103 & 0 & 0 & 0 & 0 & 0 & Base & 0.184 & 0.024 & 0.024 & 58 & 0.00375 & 0.11 & 0.5 & 0.725 & 0.085 & 0.085 & 70 & 0.0146 & 0.1 & 0.5 \\
\hline $7 \mathrm{a}$ & $\begin{array}{l}\text { Eusebia Ejecta } \\
\text { North East }\end{array}$ & 226.4 & 540 & 88,340 & 35,340 & 13,250 & 0 & 0 & $\begin{array}{l}\text { Base } \\
\text { Resurf }\end{array}$ & $\begin{array}{l}3.42 \\
1.05\end{array}$ & $\begin{array}{l}0.16 \\
0.27\end{array}$ & $\begin{array}{l}1.4 \\
0.27\end{array}$ & $\begin{array}{l}3 \\
12\end{array}$ & $\begin{array}{l}0.0949 \\
0.0215\end{array}$ & $\begin{array}{l}2 \\
0.7\end{array}$ & $\begin{array}{l}3.5 \\
1.4\end{array}$ & $\begin{array}{l}2.573 \\
1.448\end{array}$ & $\begin{array}{l}1.281 \\
0.361\end{array}$ & $\begin{array}{l}1.446 \\
0.365\end{array}$ & $\begin{array}{l}3 \\
12\end{array}$ & $\begin{array}{l}0.0532 \\
0.0294\end{array}$ & $\begin{array}{l}2 \\
0.7\end{array}$ & $\begin{array}{l}3.5 \\
1.4\end{array}$ \\
\hline & & & & & & & & & Resurf & 0.208 & 0.012 & 0.012 & 252 & 0.00424 & 0.16 & 0.5 & 0.711 & 0.037 & 0.037 & 339 & 0.0143 & 0.15 & 0.5 \\
\hline $7 \mathrm{~b}$ & Eusebia Ejecta & 42.71 & 363 & 93,660 & 70,250 & 0 & 0 & 0 & Base & 3.4 & 0.17 & 1.5 & 3 & 0.0917 & 0.9 & 2 & 3.685 & 0.734 & 2.030 & 3 & 0.0787 & 0.9 & 2 \\
\hline & South & & & & & & & & Resurf & 0.213 & 0.014 & 0.014 & 209 & 0.00433 & 0.11 & 0.45 & 0.868 & 0.047 & 0.047 & 321 & 0.0175 & 0.08 & 0.45 \\
\hline $7 \mathrm{c}$ & $\begin{array}{l}\text { Eusebia lobate } \\
\text { material } 1\end{array}$ & 15.26 & 193 & 0 & 0 & 0 & 0 & 0 & Base & 0.138 & 0.018 & 0.018 & 61 & 0.00281 & 0.1 & 0.35 & 0.562 & 0.051 & 0.051 & 116 & 0.0113 & 0.07 & 0.35 \\
\hline $7 \mathrm{~d}$ & Eusebia lobate & 7.144 & 107 & 0 & 0 & 0 & 0 & 0 & Base & 0.144 & 0.023 & 0.023 & 40 & 0.00294 & 0.09 & 0.3 & 0.666 & 0.092 & 0.092 & 51 & 0.0134 & 0.08 & 0.25 \\
\hline
\end{tabular}




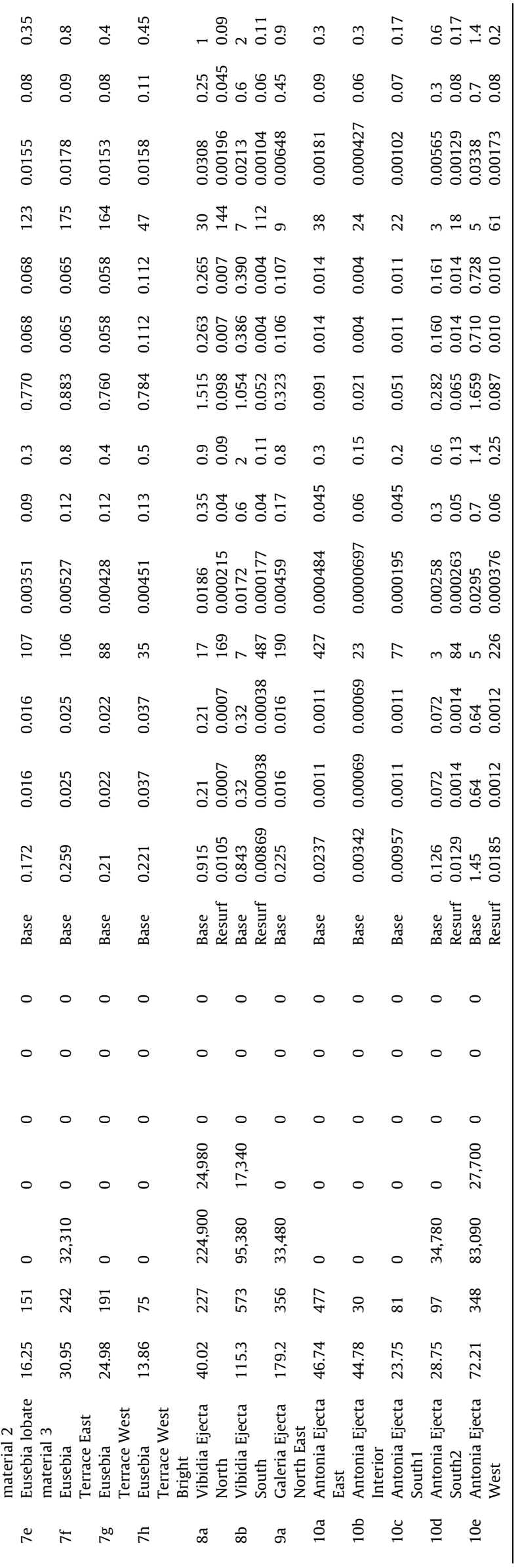

shape of the observed CSFDs, especially in close vicinity to impact craters. Thus, we interpret resurfacing signatures in close vicinity to impact craters to have been caused by the formation of the craters.

In reverse-cumulative CSF diagrams, as used in this work, the small-diameter portion of the CSFD curve also contains the large craters that were formed before the resurfacing event began. This leads to an over-estimation of the resurfacing age if the small-diameter portion of the CSFD curve is fitted directly. Thus, the small-diameter portion needs to be corrected for this effect (Werner, 2005; Michael and Neukum, 2010). This is done by removing all observed large-diameter craters from the CSFD and estimating the larger population as it would appear if it matched the age of the younger, small-diameter segment of the CSFD (Michael and Neukum, 2010).

\subsection{Morphometric measurements}

Maximum and minimum rim elevations of prominent impact craters were extracted from topographic profiles along the crater rims. Minimum crater elevations (crater floor elevations) were determined by extracting the minimum DTM pixel values within the mapped crater rim, i.e., the lowest point within the crater. Due to Vesta's significant relief compared with its radius, topography has an important influence on crater morphologies (Jaumann et al., 2012b). Thus, the determination of crater depths has to take into account the slope of the preexisting plane (Vincent et al., 2012b, 2013). In order to accomplish that, we compute a leastsquare plane through the crater rim and determine the deepest point within the impact crater perpendicular to the fitted plane. This has been accomplished by subtracting the original DTM from the interpolated plane, leading to a raster dataset representing the distance between the fitted plane and the crater floor that is directed towards the center of the reference body. In order to determine the depth perpendicular to the fitted plane, we multiplied this dataset with the sine of the angle between the vertical of the reference body and the fitted plane. Errors given in Table 2 represent the individual RMS error of the least square plane fitted through the rim of the crater plus the point accuracy of the DTM.

Crater diameters are given as minimum, maximum, and mean extents of the crater rims, respectively. As described in Section 2.2, measured diameters had to be corrected for distortions induced by the elevation level of the craters. Ejecta extents as stated in Table 2 are given as approximate average values but only for the parts of the craters where the ejecta blanket was not subsequently modified, e.g., by creep or landslides on slopes.

Depth-to-diameter ratios of the investigated craters were calculated using the crater depth as described above and the average diameter of the crater. As already mentioned by Vincent et al. (2013), the total errors of the depth-to-diameter ratios represent a combination of the uncertainties in the crater diameter $(\Delta D)$ and the uncertainties in the crater depth $(\Delta d)$ and can be expressed by:

$\Delta \frac{d}{D}=\frac{d}{D} \times\left(\frac{\Delta d}{d}+\frac{\Delta D}{D}\right)$

where $\Delta D$ is defined by our minimum and maximum measured crater diameters and $\Delta d$ is the crater-depth error as stated above.

\section{Mapping results}

\subsection{Cratered highlands material (ch)}

Description: In the Tuccia quadrangle unit ch is located on the plateau of Vestalia Terra at the northern boundary. It is mainly 
characterized by a very high crater density and an intermediate albedo (Yingst et al., 2013; Williams et al., this issue-a). Only two small occurrences of unit ch were mapped, one in the eastern part of Vestalia Terra and one in the western part. Both occurrences extend to the north into quadrangle Numisia (see Buczkowski et al., this issue). The western occurrence of unit ch is located directly north of the Vibidia crater. The eastern part of unit ch contains a crater chain, which might consist of secondary craters possibly having their origin from an unnamed $20 \mathrm{~km}$-diameter crater at the eastern edge of the plateau.

Interpretation: Yingst et al. (2013) interpreted unit ch to be ancient terrain, possibly the oldest terrain on Vesta. The unit was subsequently heavily re-worked by impacts and was possibly superimposed at least partly by Rheasilvia ejecta (Raymond et al., 2013). The surface of the western occurrence of unit ch is likely superimposed by thin ejecta of the Vibidia crater.

The locations of the two CSFD measurement areas (ID 4a and $4 \mathrm{~b})$ are shown in Fig. 1. As stated above, the CSFD on the eastern part of unit ch might be affected by an elongated cluster of secondary craters. However, the derived age on this part is not affected by these possible secondary craters, because their diameter-range was not used for the CSFD analysis. The resulting ages for unit ch are $3.67+0.05 /-0.08 \mathrm{Ga}$ (ID $4 \mathrm{a}$ ) for the western and $3.53+0.07$ / $-0.14 \mathrm{Ga}$ (ID $4 \mathrm{~b}$ ) for the eastern part of unit ch (see Fig. $5 \mathrm{~A}$ ).

\subsection{Cratered plains material ( $c p)$}

Description: The surface of unit $\mathrm{cp}$ is smoother than the surface of unit ch and shows fewer impact craters. Unit cp was mapped in two locations in quadrangle Tuccia. The first part is located in the southern part of the plateau of Vestalia Terra reaching a height of $\sim 19.6 \mathrm{~km}$ above the vestan ellipsoid (Fig. 6D). The center of this part of unit cp (at approx. $23^{\circ} \mathrm{S}$ and $230^{\circ} \mathrm{E}$ ) exhibits a set of arcuate rilles aligned in NW-SE direction. The west and southwest of this part of unit cp are affected by the ejecta blankets of Vibidia and Galeria. The second portion of unit $\mathrm{cp}$ is located in the north-eastern region of quadrangle Av-13 and is partly defined by its topography. This part of the unit is a plateau below the southern scarp of Vestalia Terra and includes several arcuate rilles and weak scarps comparable to those on unit Rrg and Rs.

Interpretation: Yingst et al. (2013) interpreted the smooth cratered plains adjacent to the Rheasilvia basin to be terrain degraded by the formation of Rheasilvia or possibly to represent Rheasilvia ejecta. In quadrangle Tuccia this interpretation should especially apply to the part of unit cp on Vestalia Terra as this region represents the basin rim of Rheasilvia (Jaumann et al., 2012b). As stated above, the second part of unit cp unit forms a plateau approximately $10 \mathrm{~km}$ below the southern scarp of Vestalia Terra and shows an almost planar surface. This might indicate that the plateau was formed as a cohesive slumping block that originally belonged to the southernmost part of Vestalia Terra, i.e., the former rim of Rheasilvia.

The CSF measurement areas (ID 1a and 1b) are shown in Fig. 1. The resulting CSFD on the north eastern part of the unit (ID 1a) provides an age of $3.41+0.15 /-1.1 \mathrm{Ga}$ that is not well constrained due to the limited statistics. Furthermore, the shape of the CSFD might indicate a resurfacing event affecting this portion of unit cp. The age derived using the resurfacing correction is $1.13 \pm 0.13 \mathrm{Ga}$. This resurfacing signature might be related to the formation of the Drusilla crater $\left(15.1^{\circ} \mathrm{S}, 261.4^{\circ} \mathrm{E}\right)$ whose ejecta blanket is located north of unit cp and possibly partially obliterated small craters in the measurement area. Alternatively, this resurfacing signature might indicate the formation age of the terrace. The second measurement area of unit cp (ID 1b) on Vestalia Terra provides an age of $2.99+0.37 /-1.1 \mathrm{Ga}$.

\subsection{Rheasilvia smooth material (Rs)}

Description: Unit Rs represents the topographic transition zone between the lower floor of Rheasilvia and the higher-relief equatorial regions of Vesta. Unit Rs is characterized by a relatively smooth surface (see Fig. 6B) that is, mainly in the eastern part, interrupted by a few isolated ridge, groove, and scarp features. However, these features are less distinctive compared to those in unit Rrg. The surface of unit Rs is covered by small impact craters. The transition to unit Rrg is unclear and, thus, the contact could only be mapped as an approximate boundary.

Interpretation: Unit Rs likely consists of ejecta emplaced during the Rheasilvia impact event also covering the floor of the Veneneia basin (Yingst et al., 2013; Williams et al., this issue-a). In order to minimize the influence of slope-related processes on the CSFD used for the stratigraphic classification of unit Rs, we only used the western and eastern part of the unit for the CSF analysis.

Table 2

Morphometric parameters of prominent impact craters in quadrangle Av-13.

\begin{tabular}{|c|c|c|c|c|c|c|c|c|c|c|c|}
\hline $\begin{array}{l}\text { Crater } \\
\text { name }\end{array}$ & $\begin{array}{l}\text { Min rim elevation } \\
\text { (km above } \\
\text { ellipsoid) }\end{array}$ & $\begin{array}{l}\text { Max rim elevation } \\
\text { (km above } \\
\text { ellipsoid) }\end{array}$ & $\begin{array}{l}\text { Crater floor } \\
\text { elevation ( } \mathrm{km} \text { above } \\
\text { ellipsoid) }\end{array}$ & $\begin{array}{l}\text { Crater } \\
\text { depth } \\
(\mathrm{km})\end{array}$ & $\begin{array}{l}\text { Depth } \\
\text { error } \\
(\mathrm{km})\end{array}$ & $\begin{array}{l}D \\
\max \\
(\mathrm{km})\end{array}$ & $\begin{array}{l}D \\
\min \\
(\mathrm{km})\end{array}$ & $\begin{array}{l}D \\
\text { mean } \\
(\mathrm{km})\end{array}$ & $\begin{array}{l}\text { Depth/ } \\
\text { diameter } \\
\text { ratio }\end{array}$ & $\begin{array}{l}\text { Depth/ } \\
\text { diameter } \\
\text { ratio error }\end{array}$ & $\begin{array}{l}\text { Mean ejecta } \\
\text { diameter } \\
(\mathrm{km})\end{array}$ \\
\hline Antonia & -15.7 & -11.5 & -17.3 & 3.3 & \pm 0.3 & 15.6 & 14.8 & 15.2 & 0.214 & \pm 0.026 & 63.2 \\
\hline Tuccia & -4.1 & -2.9 & -6.0 & 2.5 & \pm 0.2 & 9.9 & 9.2 & 9.5 & 0.262 & \pm 0.031 & 31.8 \\
\hline Eusebia & -7.5 & -2.6 & -10.5 & 5.3 & \pm 0.4 & 29.2 & 25.9 & 27.6 & 0.191 & \pm 0.025 & 87.1 \\
\hline Vibidia & 12.7 & 14.2 & 11.5 & 1.8 & \pm 0.1 & 8.6 & 7.8 & 8.2 & 0.223 & \pm 0.025 & 43.4 \\
\hline Galeria & 12.5 & 18.6 & 9.9 & 5.9 & \pm 0.6 & 25.1 & 22.8 & 23.9 & 0.255 & \pm 0.035 & 45.6 \\
\hline
\end{tabular}

Table 3

Geologic units mapped in the detail maps only.

\begin{tabular}{|c|c|c|}
\hline Unit & Description & Interpretation \\
\hline Crater wall material $(\mathrm{cw})$ & $\begin{array}{l}\text { Material on steep crater slopes. Appears fine-grained and mostly } \\
\text { smooth. Partly superimposed by dark material moving down-slope }\end{array}$ & $\begin{array}{l}\text { Impact-related material that subsequently moved } \\
\text { downslope }\end{array}$ \\
\hline Bright crater floor material (bcf) & $\begin{array}{l}\text { Mapped on the western part of Antonia's crater floor. Relatively } \\
\text { smooth, high-albedo deposit. Partly extends to the crater rim. Partly } \\
\text { covered by dark material moving down-slope }\end{array}$ & $\begin{array}{l}\text { Asymmetrically ejected, bright ejecta material of Antonia. } \\
\text { Likely pristine surface regolith }\end{array}$ \\
\hline Dark crater floor material (dcf) & $\begin{array}{l}\text { Mapped on the eastern part of Antonia's crater floor. Rougher and } \\
\text { darker than unit bcf. Material shows lobe-shaped margins and lobate } \\
\text { linear features on the deposit's surface }\end{array}$ & $\begin{array}{l}\text { Likely a mixture of excavated dark material and pristine } \\
\text { surface regolith. Originally emplaced on the crater wall but } \\
\text { subsequently moved downwards }\end{array}$ \\
\hline
\end{tabular}


CSFDs on unit Rs (measurement IDs 2a and 2b) in quadrangle Tuccia differ from east to west (see Figs. 1 and 5C). Concerning the statistical errors of the measurement on unit Rrg (ID 3a) and the measurement on the eastern part of Rs (ID 2a) ( $R r g$ $2.31 \pm 0.32 \mathrm{Ga}$; Rs $2.47 \mathrm{Ga}+0.55 /-0.63 \mathrm{Ga}$ ), the resulting age on the eastern part of unit Rs is comparable to unit Rrg. However, due to the smaller measurement area and, thus, the lower absolute number of large impact craters, the CSFD does not fit the PF as well as the CSFD on unit Rrg. On the western part of unit Rs (ID 2b), i.e.
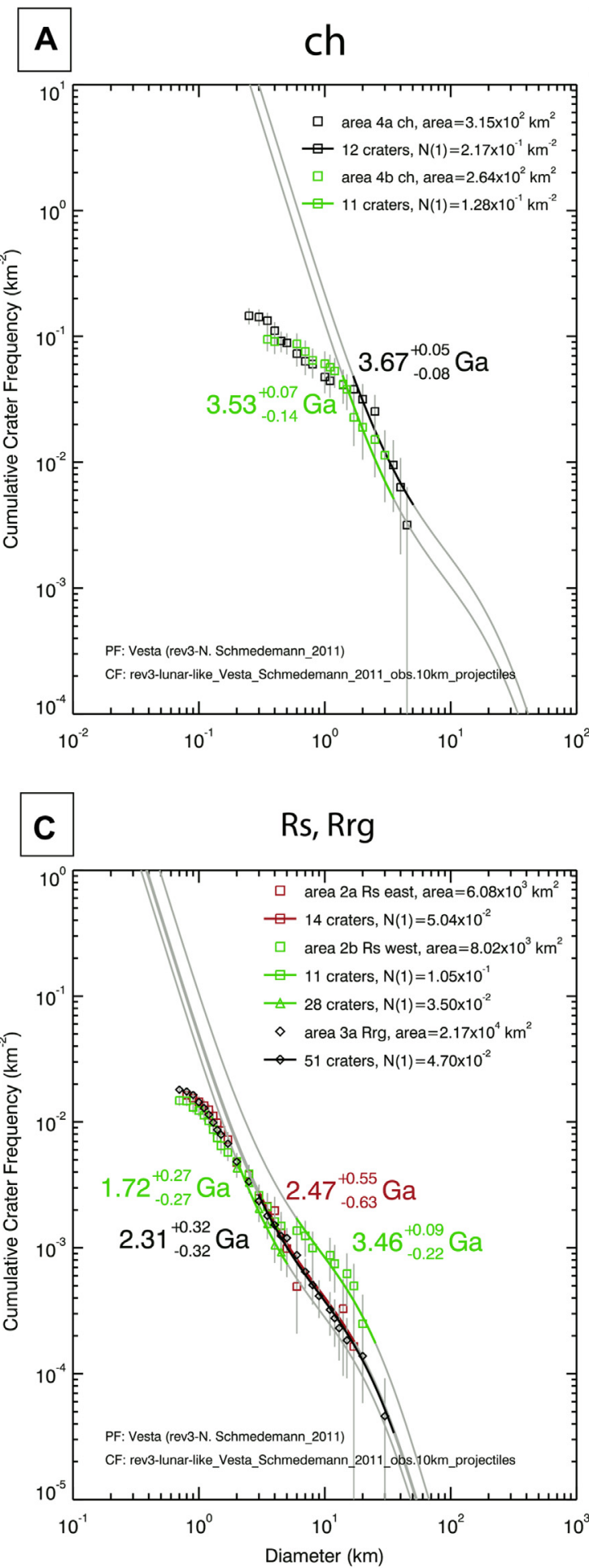

on the former floor of the Veneneia basin, the CSFD indicates a surface age of $3.46+0.09 /-0.22 \mathrm{Ga}$. Additionally, the shape of the CSFD suggests that there might have been a resurfacing process which ended $\sim 1.7 \mathrm{Ga}$ ago.

\subsection{Rheasilvia ridge-and-groove material ( $\mathrm{Rrg}$ )}

Description: Unit Rrg covers approximately the southern half of the Tuccia quadrangle, i.e., most of the floor of the Rheasilvia basin.

\section{B $\mathrm{CP}$}

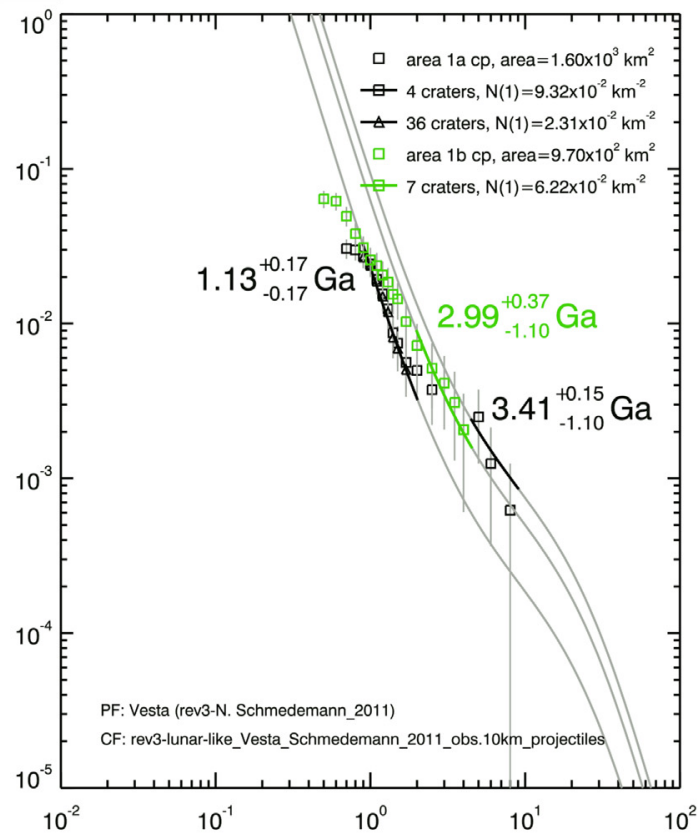

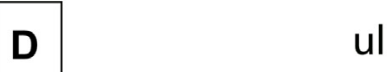

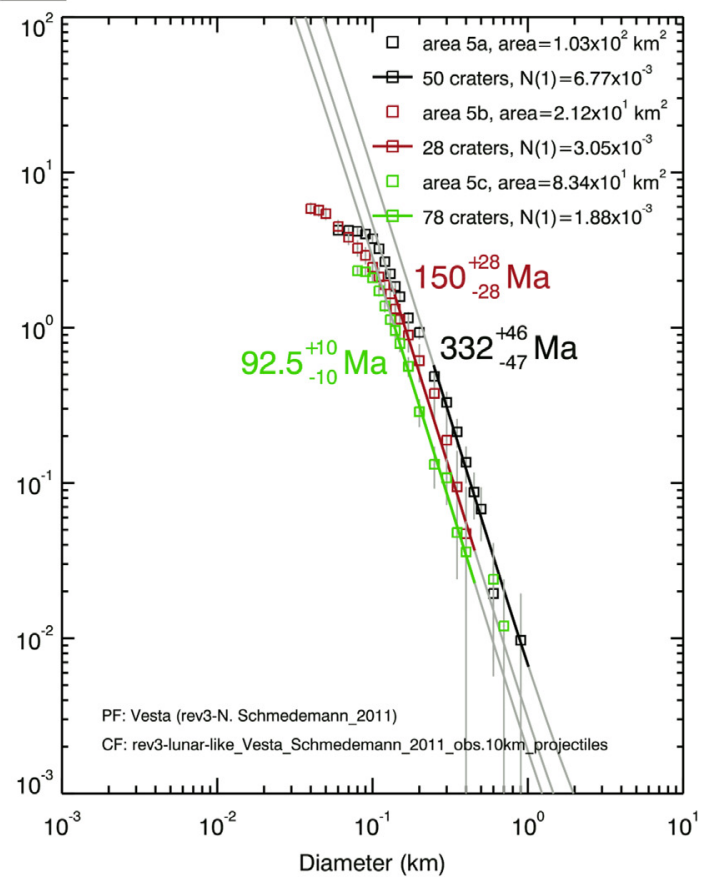

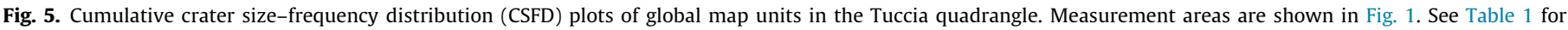
measurement details. 



Fig. 6. Type areas of material units. All images are excerpts from $\mathrm{FC}$ clear-filter images $(\mathrm{H}=\mathrm{HAMO}, \mathrm{L}=\mathrm{LAMO})$. Coordinates are given for the centers of the excerpt. (A) Rheasilvia ridge-and-groove material (Rrg). H FC21A0010158, 237. $7^{\circ} \mathrm{E} / 48.2^{\circ} \mathrm{S}$. (B) Rheasilvia smooth material (Rs). H FC21 A0011228, 246.6 ${ }^{\circ} \mathrm{E} / 36.4^{\circ} \mathrm{S}$. (C) Rheasilvia scarp wall material (Rsw). H FC21 A0028591, 239.3을 $29.5^{\circ} \mathrm{S}$. (D) Cratered plains material on Vestalia Terra (cp). H FC21A0010354, $237.1^{\circ} \mathrm{E} / 23.2^{\circ} \mathrm{S}$. (E) Cratered highlands material (ch) at the quadrangle boundary north of Vibidia. H FC21A0011068, $217.2^{\circ} \mathrm{E} / 22.0^{\circ} \mathrm{S}$. (F) Undifferentiated lobate material (ul) at the base of the southern scarp of Vestalia Terra. $\mathrm{H}$ FC21A0010570, $223^{\circ} \mathrm{E} / 35^{\circ} \mathrm{S}$. (G) Undifferentiated lobate material (ul) on the floor of an unnamed crater. White arrows denote lobate boundaries of the deposit. L FC21A0014345, $189.8^{\circ} \mathrm{E} / 21.6^{\circ} \mathrm{S}$. (H) Dark lobate material (dl) at the north-eastern edge of the quadrangle. White arrows indicate the ambiguous boundaries of the small branch of this halo unit extending from quadrangle Av-14 into Av-13. L FC21A0024898, 269.1 ${ }^{\circ} \mathrm{E} / 22.3^{\circ} \mathrm{S}$. (I) Bright crater ray material (bcr) ejected from a crater on the rim of crater Tuccia. L FC21A0017230, $199.5^{\circ} \mathrm{E} / 39^{\circ} \mathrm{S}$. (J) Dark crater ray material (dcr) of a small unnamed crater on unit Rrg. White arrow denotes a clear dark ray. L FC21A0016978, $260^{\circ} \mathrm{E} / 54.6^{\circ} \mathrm{S}$. (K) Complex crater ray material (ccr) ejected by Vibidia. L FC21A0016046 and FC21 A0014743, 220.9 ${ }^{\circ} \mathrm{E} / 26.1^{\circ} \mathrm{S}$. (L) Bright crater material (bc) east of Antonia. White arrows denote linear ejecta features. L FC21 A0014417, $215^{\circ} \mathrm{E} / 59^{\circ} \mathrm{S}$. (M) Dark crater material (dc) in the center and south of Antonia crater showing a straight boundary (white arrows) to other units. L FC21A0014924, $201.5^{\circ} \mathrm{E} / 60.5^{\circ} \mathrm{S}$. (N) Undifferentiated crater material (uc) of a small impact crater $(D=\sim 2.5 \mathrm{~km})$. Differences in albedo and texture allow for the identification of uc. L FC21A0026372, $183.9^{\circ} \mathrm{E} / 44.7^{\circ} \mathrm{S}$. (O) Dark material (d) outcrops (white arrows) at the crater wall of Galeria. L FC21A0023133, $230.5^{\circ} \mathrm{E} / 28.8^{\circ} \mathrm{S}$. (P) Crater wall material (cw) in Eusebia. L FC21 A0014750, 202.8 $\mathrm{E} / 40.6^{\circ} \mathrm{S}$. (Q) Dark crater floor material (dcf) in Antonia. L FC21 A0014923, 201.7 ${ }^{\circ} \mathrm{E} / 58.7^{\circ} \mathrm{S}$. (S) Bright crater floor material (bcf) in Antonia. L FC21A0014923, 200.0 $\mathrm{E} / 58.9^{\circ} \mathrm{S}$. 
The unit is characterized by different sets of ridges, grooves, and scarps at kilometer scale (see Fig. 6A). The slope/scarp surfaces are smoother than the plains and show no distinct texture. Surfaces in between the scarps, ridges, and grooves are covered by small impact craters and often show traces of ejecta blankets, i.e., linear or flow-like surface features. The unit is superimposed by several craters including Eusebia and Antonia showing low and high-albedo ejecta blankets. Nevertheless, the characteristic relief of unit Rrg is still visible through the ejecta blankets.

Interpretation: Following Yingst et al. (2013), unit Rrg consists of Rheasilvia basin material, heavily disrupted by post-impact processes. It is likely the result of extensive gravity-driven mass wasting processes - slumps and landslides - in the interior of the Rheasilvia basin. The smoother slope/scarp surfaces are possibly the result of creep or impact-induced seismic shaking.

As described by Yingst et al. (2013), the Rheasilvia ridge-andgroove material ( $\mathrm{Rrg}$ ) was named after the different sets of ridges and grooves on the floor of Rheasilvia identified on the image data acquired in the early phases of the Dawn mission (Survey orbit) (Russell et al., 2012). However, looking at the slope map and topographical data derived from the HAMO and LAMO phases (draped over an elliptical reference body) many of these features do not show a symmetrical shape, i.e., the features identified as grooves are not topographic lows and features identified as ridges are not topographic highs (see Fig. 2D). In particular, this can be observed in the topographic profile presented in Fig. 4C. Instead of being ridges and grooves, most of these features only have one sloped surface and, thus, were mapped as scarps.

In order to derive a CSFD that is representative for the regional character of unit Rrg in the quadrangle, the craters Eusebia, Tuccia, and Antonia with their large ejecta blankets were included in the area used for the crater measurement. Although these craters form their own geologic units (crater materials) and thus were not mapped as Rrg, they post-date unit Rrg and have to be used for the age determination. The boundary of the combined measurement area is shown in Fig. 1 (white polygon, ID 3a). The derived CSFD of unit Rrg as shown in Fig. 5C follows the expected production function provided by Schmedemann et al. (submitted for publication) in the $3-30 \mathrm{~km}$ diameter range. The expected resurfacing due to slope processes or to the coverage by ejecta blankets seems not to have been efficient enough to erode or erase craters in the measured diameter range. Using the $\mathrm{CF}$ and $\mathrm{PF}$ of Schmedemann et al. (submitted for publication) the CSFD provides a surface age of $2.31 \mathrm{Ga} \pm 0.32 \mathrm{Ga}$ that reflects the last large-scale activity on the floor of the Rheasilvia basin (see Fig. 7). Applying the CF and PF of O'Brien and Marchi et al. (O'Brien, 2013) the resulting age for this CSFD would be $\sim 1.12 \mathrm{Ga}+128 /-129 \mathrm{Ma}$ (right column in Fig. 7) Marchi et al. (2012) and Schenk et al. (2012a) interpreted the CSFD on the floor of Rheasilvia to represent the formation age of the basin.

\subsection{Rheasilvia scarp wall material (Rsw)}

Description: The surface of unit Rsw is smoother than the surroundings and shows lower frequencies of impact craters (see Fig. 6C). In the Tuccia quadrangle unit Rsw is mainly located on the steep slope of the southern scarp of Vestalia Terra. Furthermore, there is a small occurrence of unit Rsw at the western quadrangle boundary at $\sim 40^{\circ} \mathrm{S}$ and $180^{\circ} \mathrm{E}$. This occurrence belongs to the north-eastern portion of Agonium Rupes, a large scarp in the Sextilia Quadrangle Av-12 (Krohn et al., 2012; Krohn et al., this issue). The surface of unit Rsw is comparable to the material on the much smaller scarps within unit Rrg.

Interpretation: The most likely explanation for the smooth surface of unit Rsw is the influence of gravity-driven mass wasting on steep slopes. Processes like creep or impact-induced seismic shaking erase small impact craters or surface features on slopes (e.g., Titley, 1966; Richardson et al., 2005; Platz et al., 2013) leaving a surface much smoother than the surrounding areas. Unit Rsw likely consists of unit Rs or Rrg subsequently modified by gravitydriven mass movement. Due to these ongoing processes it is impossible to determine a reliable CSFD-based formation age for unit Rsw (i.e., the formation age of the scarp itself) as the derived CSFDs will only provide information about the latest activity on the slope. Thus, no CSF measurements were conducted on unit Rsw.

\subsection{Undifferentiated lobate material (ul)}

Description: Unit ul is characterized by relatively smooth-textured to hummocky surfaces and lobate margins. The unit is mainly located on the floors of impact craters (Fig. 6G) or at the bases of large scarps, e.g., the two fan-shaped deposits at the southern scarp of Vestalia Terra (see Fig. 6F). Generally, the crater densities are lower than on the surrounding material. The albedo in FC clear filter images is similar to the surroundings and there is no distinctive color in the color ratio maps.

Interpretation: Williams et al. (2013) interpreted a few discrete smooth lobate deposits within or close to impact craters to be suggestive of impact melts. Many other lobate deposits were interpreted to be associated with gravity driven mass movements, including rotational landslides, slumps, or talus accumulations (Williams et al., 2013; Yingst et al., 2013). In quadrangle Av-13 the floor of Eusebia is especially affected by smooth undifferentiated lobate material. CSFD measurements on this unit are presented in the Eusebia Section 4.1.2. These CSF analyses indicate younger surface ages for the smooth undifferentiated lobate materials than for the ejecta blanket of Eusebia itself. This would be consistent with an emplacement related to subsequent landslide events and inconsistent with an impact melt-related deposition of the smooth lobate material. We interpret most occurrences of unit ul in quadrangle Tuccia, in particular the ones with hummocky surfaces, to be associated with gravity-driven mass wasting processes triggered by, for example, impact-induced seismic shaking (e.g., Titley, 1966; Richardson et al., 2005) or slope failure due to overburden. The mapped deposits are either slump deposits, where the material moved as more or less intact blocks, or landslide deposits, where the moved material appears loose/incoherent. Generally, mass movements seem to be very common in quadrangle Tuccia because almost the entire southern half of the quadrangle consists of the Rheasilvia ridge-and-groove material (Rrg), which is thought to consist of huge gravity-driven slumps and landslides towards the floor of Rheasilvia (Jaumann et al., 2012b; Schenk et al., 2012a; Yingst et al., 2013). Because gravity-driven mass wasting processes are related to steep slopes, the southern scarp of Vestalia Terra still provides very good conditions for the development of mass movements like landslides or slumps. Similar conditions are found on the steep interior slopes of impact craters.

CSFDs on the surfaces of unit ul only provide information about the latest activity phase of the mass wasting process, which does not necessarily reflect the emplacement age of the entire mass wasting deposit. Three deposits were dated: two at the scarp of Vestalia Terra (IDs 5a and 5c) and one local landslide within the unit Rrg (ID 5b). The corresponding CSFD plots are shown in Fig. 5D and indicate surface ages of $92.5 \pm 10 \mathrm{Ma}, 150 \pm 28 \mathrm{Ma}$, and $332+46 /-47 \mathrm{Ma}$. These very young surface ages indicate ongoing gravity-driven mass wasting activity in the Rheasilvia basin. It should be noted here that the mapped local/regional mass wasting deposits were identified by their pristine morphology, i.e., by their clear boundaries. Thus, it is likely that several older landslide or slump deposits, which were emplaced in between the age determined for the whole unit $\operatorname{Rrg}(2.31 \mathrm{Ga})$ and the very young ages determined for the small scale events presented above, were not identified and mapped due to their degradation state. 


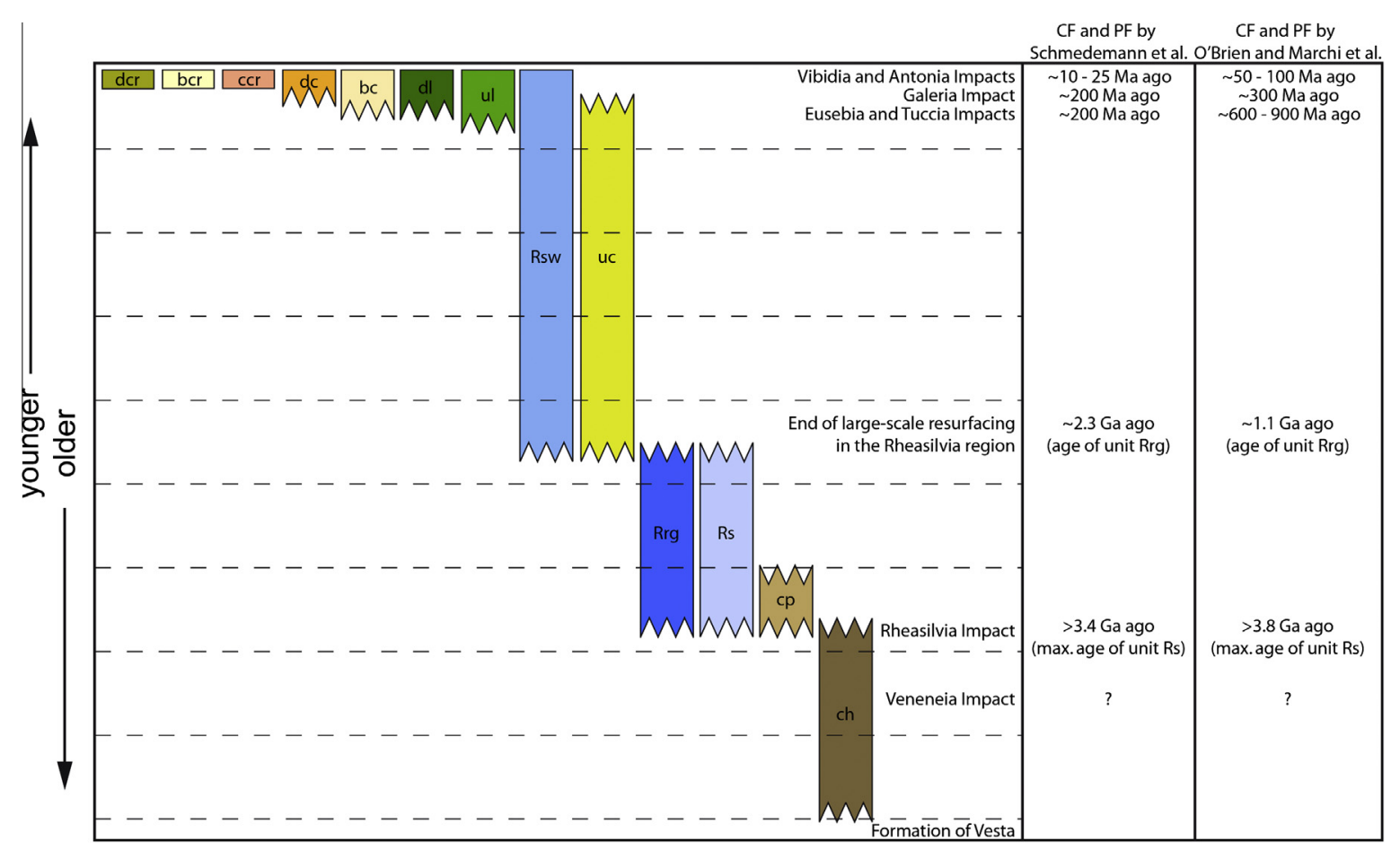

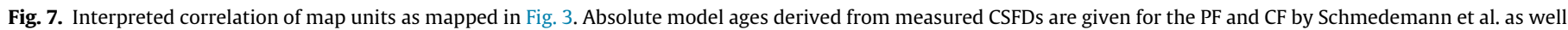
as for the functions by O'Brien and Marchi et al.

Further information on mass wasting processes in the Rheasilvia region are given by Otto et al. (2013).

\subsection{Dark lobate material (dl)}

Description: Unit dl has a slightly lower albedo than the surrounding area and its surface has a relatively smooth appearance only interrupted by small impact craters (see Fig. $6 \mathrm{H}$ ). There is only one small occurrence of unit $\mathrm{dl}$ at the eastern boundary of quadrangle $\mathrm{Av}-13$ that is an elongated extension of the dark lobate material unit in quadrangle Av-14 Urbinia (Mest et al., 2012).

Interpretation: Mest et al. (2012) interpreted the directly connected occurrence of unit $\mathrm{dl}$ in quadrangle Av-14 Urbinia possibly to consist of lobate ejecta or to suggest the locations of ancient lava flows (Mest et al., 2012).

\subsection{Crater materials (uc, bc, dc, bcr, dcr, ccr)}

Description: As described by Yingst et al. (2013) crater materials on Vesta's surface can be divided into several subunits. Undifferentiated crater material (uc) contains crater rims, floors, and continuous ejecta blankets showing a smoother/less-densely cratered surface than the surroundings. The albedo of unit uc in FC clear filter images is similar to the surroundings and the unit is not conspicuous in the color ratio map. Bright crater material (bc) also contains crater rims, crater floors, and continuous ejecta blankets mantling the underlying surface but has a higher albedo in FC clear filter images than the surroundings. The ejecta blankets are characterized by very smooth surfaces sometimes with radial, linear, or flow-like surface features. In the color ratio maps unit bc appears yellowish to greenish. Dark crater material (dc) was only observed at the southern rim and on the southern ejecta blanket of Antonia crater. Unit dc shows an overall lower albedo than the surrounding areas but consists of a mixture of dark and bright ejecta patches. It is partly characterized by linear features as well as boulders. Unit dc has a bluish appearance in the color ratio map. In addition to these units, fresh impact craters often show ray materials that can be subdivided into dark crater ray material (dcr) and bright crater ray material (bcr). At Vibidia crater, complex crater ray material (ccr) was also observed. Units bcr, dcr, and ccr form radial streaks, rays, or patches of halo material that mantles the underlying surface up to a distance of six crater diameters radially from the crater rim (bright rayed crater on the rim of Tuccia). Here, unit bcr is distributed relatively symmetrically, whereas dcr and ccr are asymmetrically distributed around impact craters. The appearance in the color ratio maps is yellowish to greenish for bcr, bluish for $\mathrm{dcr}$, and bluish to greenish for ccr.

Interpretation: All crater material units mentioned above were emplaced by impact processes. Here, unit uc seems to be the oldest among the crater material units as its spectral signature and the typical linear ejecta features have already vanished. The relatively high albedo of unit bc compared to the surroundings indicates that the ejecta material was relatively recently exposed to the surface (Pieters et al., 1993, 2012; Reddy et al., 2012b). Furthermore, the yellowish to greenish appearance of unit bc in the color ratio map suggests relatively fresh crater deposits because the green band is primarily a function of mafic mineral absorption band depth, indicating relatively pristine/un-weathered mafic minerals (Reddy et al., 2012a, 2012b). Unit dc is probably a mix of lowand high-albedo, relatively fresh crater materials emplaced by impact processes. Here, the dark material patches are possibly excavated from low-albedo lenses/layers in the subsurface (see Sections 3.9 and 4.3). Crater ray materials (units bcr, dcr, and ccr) seem to be the most freshly exposed and least weathered among the ejecta materials as typically only the youngest impact structures show distinct crater rays (e.g., Hapke, 2001). Comparable to unit bc, unit bcr likely consists of fresh high albedo materials excavated from Vesta. Unit dcr possibly consists of low albedo materials excavated from subsurface layers or lenses of dark material. Alternatively, unit dcr could consist of low-albedo material 
delivered by the impactor (see Section 2.1, Reddy et al., 2012a, 2012b). Unit ccr seems to consist of a mixture of bcr and dcr.

In order to determine the formation ages of the prominent impact craters we measured CSFDs on the continuous ejecta blankets and crater floors of the respective craters. Although the ejecta thickness and consequently the ability to obliterate/cover preexisting craters decreases rapidly with increasing distance from the crater rim (e.g., McGetchin et al., 1973) most of the CSFDs measured on the relatively thin continuous ejecta blankets show clear resurfacing signatures even at distances up to one diameter from the parent rim. Here, the derived CSFDs can be used for the determination of both the age of the underlying geologic unit and the age of the emplacement of the ejecta blanket and, thus, the formation of the impact crater (see Section 2.2 for details). Ages determined in the regions of the prominent impact craters are given in their respective chapters.

\subsection{Dark material (d)}

Description: Unit d is generally characterized by a much lower albedo in comparison to the surrounding material. In color ratio maps unit $d$ appears bluish or reddish. Unit $d$ is abundant in the Tuccia quadrangle and is often seen in small outcrops mapped as point location features. In the detailed maps of the prominent impact craters, dark material was mapped as an areal material unit. When unit $\mathrm{d}$ is cut by impacts or other processes it seems that the material moves downslope as fine-grained material and builds up a thin surface layer of low-albedo material which has a slightly higher albedo than the outcrop of the dark material (see Fig. 60). Unit d mainly occurs at the boundary/scarp of Vestalia Terra, i.e., at the crater walls of Galeria, Vibidia, and three other, more degraded craters on the scarp. Furthermore, there is a small outcrop approx. $20 \mathrm{~km}$ east of Galeria (see Fig. 8). On the floor of Rheasilvia and Veneneia only two occurrences of unit d were identified, the Antonia crater region and a small unnamed impact crater at $260.3^{\circ} \mathrm{E} / 54.4^{\circ} \mathrm{S}$.

Interpretation: From spectral properties, Reddy et al. (2012a, 2012b) and McCord et al. (2012) concluded that the majority of dark material on Vesta's surface might consist of exogenic carbonaceous chondrite material, which has been seen in HED meteorites from Vesta (e.g., Buchanan et al., 1993; Zolensky et al., 1996; McSween et al., 2011). Furthermore, Reddy et al. (2012a) and Jaumann et al. (2012a) concluded from the non-uniform, spatial distribution of the dark material that the Veneneia impact event might be related to dark material's origin. In combination with dynamical modeling of the Veneneia ejecta, Reddy et al. (2012a) found that the Veneneia basin might have been formed by a low-velocity carbonaceous impactor delivering dark material to the surface of Vesta.

The spatial distribution of unit $\mathrm{d}$ as found in the Tuccia quadrangle is in agreement with the emplacement of dark material within Veneneia ejecta as proposed by Reddy et al. (2012a) and Jaumann et al. (2012a). Veneneia ejecta should have been emplaced close to the Veneneia rim on Vestalia Terra and were subsequently superposed by the thick ejecta of Rheasilvia. Consequently, the dark material layers or lenses would, in particular, be visible/ excavated at the bounding scarps of Vestalia Terra, as found in this study, and at the crater walls of larger craters on the Vestalia Terra plateau, as found by Buczkowski et al. (this issue).

\section{Geology and formation ages of prominent impact craters in AV-13 Tuccia}

\subsection{Geology of Tuccia and Eusebia craters}

Tuccia crater is located at $40^{\circ} \mathrm{S}$ and $197^{\circ} \mathrm{E}$ (Fig. $9 \mathrm{~A}$ and B) with a maximum diameter of about $10 \mathrm{~km}$ and a minimum of $9.2 \mathrm{~km}$ (see
Table 2). The bright-rayed crater on its rim has a diameter of $\sim 3 \mathrm{~km}$. Tuccia is located on top of a heavily degraded impact crater which has a diameter of $\sim 12.2 \mathrm{~km}$. The eastern rim of Tuccia is partly degraded and coincides with the eastern rim of the underlying crater structure. The western rim of Tuccia is pristine. The unnamed bright-rayed crater is located on the eastern rim of Tuccia and accordingly the underlying degraded crater. The green color of the bright crater ray material (bcr) in the color ratio map suggests that fresh material was excavated from below (see Fig. 10A). As described in Sections 2.1 and 3.8, fresh material typically has deeper pyroxene absorption bands that could be due to abundance of iron in the mineral, a particle size effect, or the absence of opaques and space weathering (Reddy et al., 2012a, $2012 b)$. In the Tuccia region it is most probably a combination of iron abundance and particle size. We draw this conclusion from the following observations. The crater is located at the boundary of the ancient Veneneia basin, the formation of which is thought to have delivered dark material to Vesta (Jaumann et al., 2012a; Reddy et al., 2012a) (see Section 3.9). Several dark material deposits are located within this large basin and this gives the overall blue color to the background surface (see Fig. 10A). The excavation of fresh material by this impact crater would suggest, a) the material excavated is deeper than any dark material layer in this region, b) there is no evidence for a subsurface dark material layer. The material excavated by two of the large impact basins in the southern hemisphere is primarily diogenitic. Diogenites are pure orthopyroxene with little or no olivine. Diogenites on average have deeper absorption bands than eucrites due to a higher abundance of pyroxene (higher total iron) (Reddy et al., 2010). They also have a larger grain size on average than eucrites or howardites (Reddy et al., 2012b).

Eusebia crater is located to the east of Tuccia at $42.5^{\circ} \mathrm{S}$ and $204.5^{\circ}$ E. Eusebia has a diameter of approx. $25.9 \mathrm{~km}$ in east-west direction. However, the diameter measured from the fresh-looking sharp northern rim to the covered/degraded southern rim amounts to approx. $29.2 \mathrm{~km}$ (see Table 2). The arrangement of scarps and slopes at the southern rim of Eusebia indicates that the former southern rim has slumped inwards forming a terrace (see Fig. 9) whose planar surface is even visible in the topographic profile in Fig. 11B. Since the southern rim of Eusebia has been displaced and the remaining degraded rim does not reflect the former rim, the true diameter of Eusebia can only be measured in east-west direction. Furthermore, the crater floor of Eusebia is covered by lobate material that is interpreted to be landslide material from the crater walls. This process might also contribute to the retreat of the crater rim. However, the amount of this additional retreat is probably small compared to the widening caused by the formation of the terrace. The subsequent modifications of Eusebia, i.e., the formation of the terrace and the related displacement of the crater rim led to a comparatively low $d / D$-ratio of 0.19 , the lowest ratio of the five prominent craters analyzed in this study (see Table 2).

\subsubsection{Age of Tuccia crater}

In order to determine the age of Tuccia we measured the crater size-frequency distributions on its ejecta in several measurement areas surrounding the impact crater (see Fig. 9A). The crater is bowl-shaped and thus crater size-frequency distributions in the interior of the crater are strongly affected by slope processes and cannot be used for a reliable determination of the age of the impact event. As mentioned in Section 4.1, the Tuccia region is characterized by several impact structures overlapping one another. Thus, the determination of the age of the Tuccia impact itself is complicated by a number of different impact-related resurfacing events (see Section 2.2). The locations of the measurement areas (IDs 6a-6e) are shown in Fig. 9A. Measured CSFDs are shown in Fig. 12A-C. The morphologies of the large-diameter craters within 



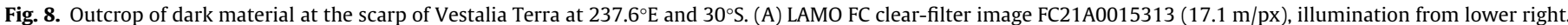

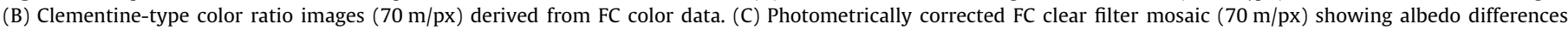
between dark-material outcrops, transported dark material and the surrounding materials.

these measurements are consistent with the impact resurfacing. These craters are mostly mantled by the ejecta blanket and/or degraded by impact-induced seismic shaking (e.g., Richardson et al., 2005; Thomas and Robinson, 2005). Thus, the CSFD of these craters provide information about the age of the underlying surface. Although these model ages (3.5 Ga [ID 6b] and 3.62 Ga [ID 6c]) have large error bars due to the low numbers of craters, they clearly indicate that the underlying surface is older than 2.6$3 \mathrm{Ga}$. The latest resurfacing event in the region took place between $\sim 160$ Ma (ID 6c) and $\sim 184$ Ma ago (ID 6e). One might think that the bright-rayed crater on Tuccia's north-eastern rim caused this resurfacing signature. However, the measurement on the southwestern ejecta blanket of Tuccia also shows a resurfacing age of $\sim 175 \mathrm{Ma}$ (ID 6b, Fig. 12A). This portion of Tuccia's ejecta blanket is not superimposed by the bright-ray crater ejecta and, thus, it is unlikely that the resurfacing event $\sim 160$ Ma to $\sim 184$ Ma ago reflects the formation age of the bright-rayed crater. Probably, the ejecta of the relatively small-diameter bright-rayed crater are too thin to reset the crater record in the measured diameter range even on the north-eastern part of Tuccia's ejecta. Consequently, the age of the bright-rayed crater cannot be determined at this resolution. Because there is no other younger mid-sized crater close to Tuccia that might be responsible for the subsequent resurfacing, we interpret the $\sim 160$ Ma to $\sim 184 \mathrm{Ma}$ age to be the formation age of Tuccia. Furthermore, this young formation age is in agreement with Tuccia's comparatively high $d / D$-ratio of 0.26 , which is the highest $d / D$-ratio of the prominent craters, even higher than the much younger, similar-sized rayed crater, Vibidia (see Table 2). The less-distinct resurfacing events in between, i.e., the event 701$764 \mathrm{Ma}$ ago (IDs 6c, 6d) or the event $2.08 \mathrm{Ga}$ ago (ID 6a), might reflect the age of the crater underlying Tuccia. For further discussion of the formation ages of the prominent craters see Section 5.

\subsubsection{Age of Eusebia crater}

CSFDs were measured on the north-eastern and southern ejecta blanket, on the eastern and western part of the terrace in the south of the crater, and on the lobate deposits on the crater floor. The locations of the measurement areas (IDs 7a-g) can be seen in Fig. 9A. The corresponding CSFDs are shown in Fig. 12D-F. Comparable to the Tuccia crater, the age of the underlying surface of Eusebia is probably older than $\sim 2-3 \mathrm{Ga}(3.40+0.17 /-1.5 \mathrm{Ga}$ [ID 7b] and $3.42+0.16 /-1.4 \mathrm{Ga}$ [ID 7a]). Both the latest resurfacing event on the ejecta blanket, as well as the ages on the terrace in the south of the crater, are in the range between $208 \mathrm{Ma}$ (ID 7a) and $259 \mathrm{Ma}$ (ID 7f). Four of the five of these measurements indicate ages between $208 \mathrm{Ma}$ and $221 \mathrm{Ma}$ (IDs 7a, b, g, h). Comparable to the adjacent Tuccia region, there are no impact structures close to Eusebia that were capable of subsequently modifying the CSFDs on Eusebia's southern and north-eastern ejecta blanket. Thus, we interpret the latest resurfacing event (208-221 Ma) to have been caused by the ejecta emplacement of Eusebia (see also Section 5). The measurement area on the north-eastern ejecta blanket might indicate an additional possible resurfacing event at $1.05 \pm 0.27 \mathrm{Ga}$ (ID 7a) which is, considering the errors of $\pm 270 \mathrm{Ma}$, comparable to the resurfacing event in the Tuccia region at 701-764 Ma (ID $6 c$, d). As mentioned in Section 4.1.1, this resurfacing event might reflect the age of the crater superposed by the Tuccia crater. The lobate deposits on the crater floor of Eusebia show a crater retention age of $\sim 140$ to $\sim 170 \mathrm{Ma}$ (IDs 7c, d, e) indicating that mass wasting processes subsequently modified Eusebia about $50 \mathrm{Myr}$ after its formation (see also Section 3.6).

\subsection{Geology of Vibidia and Galeria craters}

Vibidia crater is located at $27^{\circ} \mathrm{S}$ and $220^{\circ} \mathrm{E}$ with a diameter of $\sim 7.8-8.5 \mathrm{~km}$. Vibidia is a bowl-shaped bright-rayed crater with a $d / D$-ratio of 0.22 that also excavated dark material, which is visible on parts of the crater floor and at the eastern crater rim (see Figs. 6K and 9C). The Vibidia impact happened on the south-western edge of the Vestalia Terra highland on a moderate slope of around $10-15^{\circ}$ (see Fig. 11C). Nevertheless, Vibidia is a so-called "asymmetric" crater with a sharp, pristine rim on the uphill side of the crater and a degraded/covered rim on the downhill side (Jaumann et al., 2012b; Krohn et al., 2013). Comparable crater morphologies are observed on other bodies in the Solar System, e.g., the Moon or Lutetia (Plescia, 2012; Schenk et al., 2012b; Vincent et al., 2012a). However, asymmetric craters, which are likely the result of impacts on steep slopes (Jaumann et al., 2012b), seem to be unusually common on Vesta (Schenk et al., 2012b). Probably this is the result of Vesta's significant relief compared with its radius (Jaumann et al., 2012b). Several formation mechanisms for the asymmetric development of crater rims on Vesta were proposed by Jaumann et al. (2012b), including ballistic ejecta coverage of the down-slope rim, incomplete formation of the rim, and mass wasting processes. However, using hydrocode modeling, Krohn et al. (2013) have shown that the observed morphologies of asymmetric craters might be explained best by oblique impacts on steep slopes producing asymmetrical ejecta emplacement.

In contrast to most of the craters in the Tuccia quadrangle, a large number of blocks/boulders can be found on the floor of Vibidia as well as within a vicinity of about one diameter of the crater rim. The typical block size is around $100-150 \mathrm{~m}$. Here, the block 

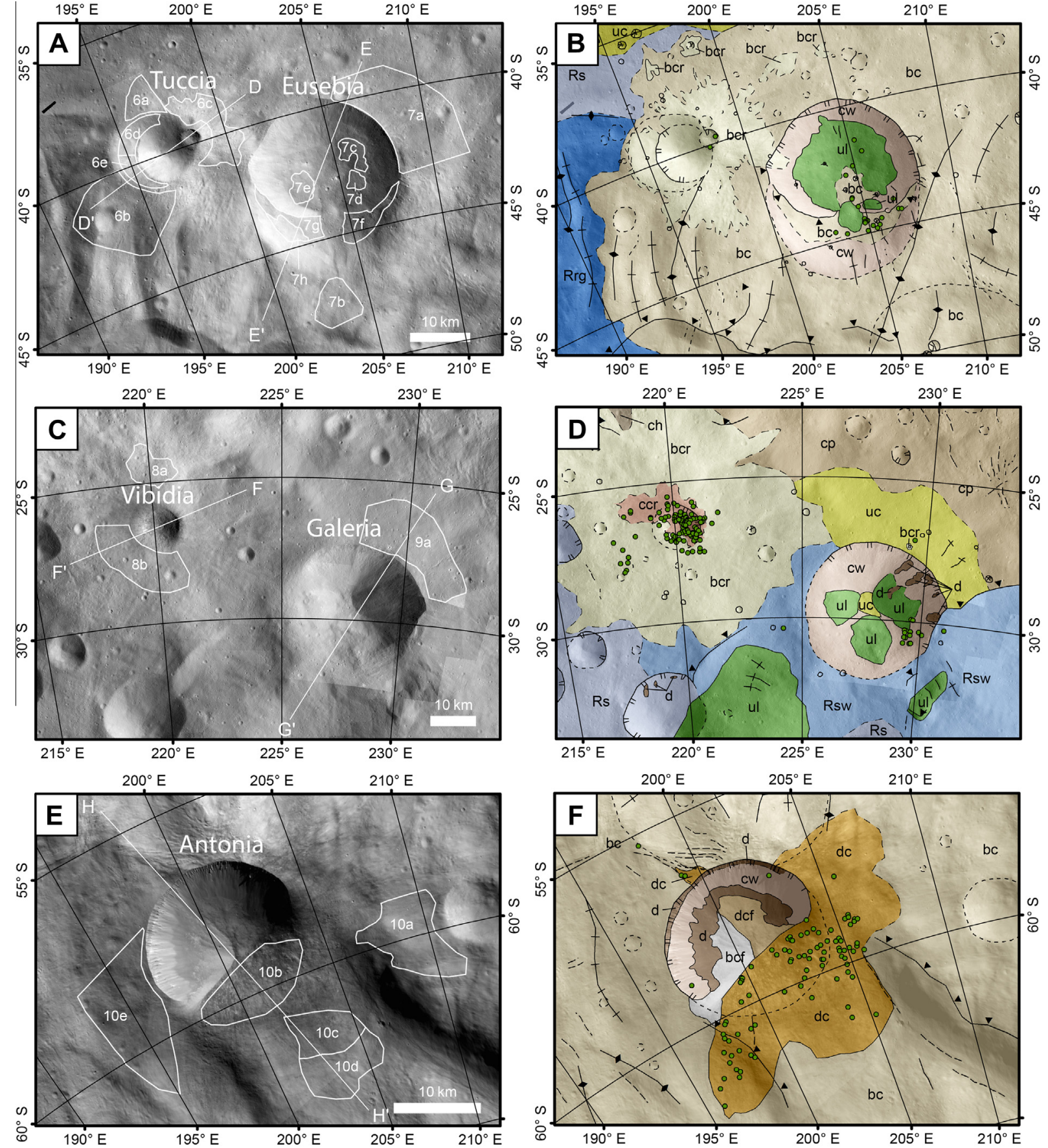

\section{Contacts}

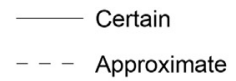

\section{Crater Rims}

П

Crest of small crater rim

...... Arcuate rill

- Boulder

\section{Lineaments}

\section{Location Features Geologic Units}

$---\cdot$ Lineament

\begin{tabular}{|c|l|}
\hline$c h$ & Cratered highlands material \\
\hline$c p$ & Cratered plains material \\
\hline$R s$ & Rheasilvia smooth material \\
\hline$R r g$ & Rheasilvia ridge-and-groove material \\
\hline$R s w$ & Rheasilvia scarp wall material \\
\hline$d$ & Dark material \\
\hline ul & Undifferentiated lobate material \\
\hline
\end{tabular}

uc Undifferentiated crater material

dc Dark crater material

bc Bright crater material

ccr Complex crater ray material

bcr Bright crater ray material

cW Crater wall material

bcf Bright crater floor material

dcf Dark crater floor material

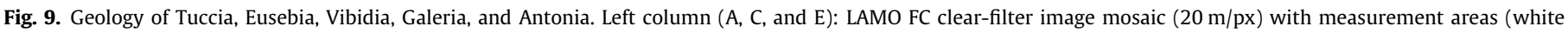

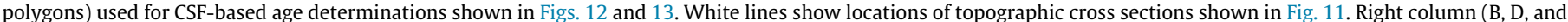

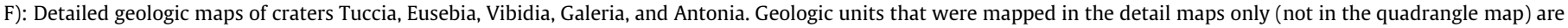
described in Table 3. 

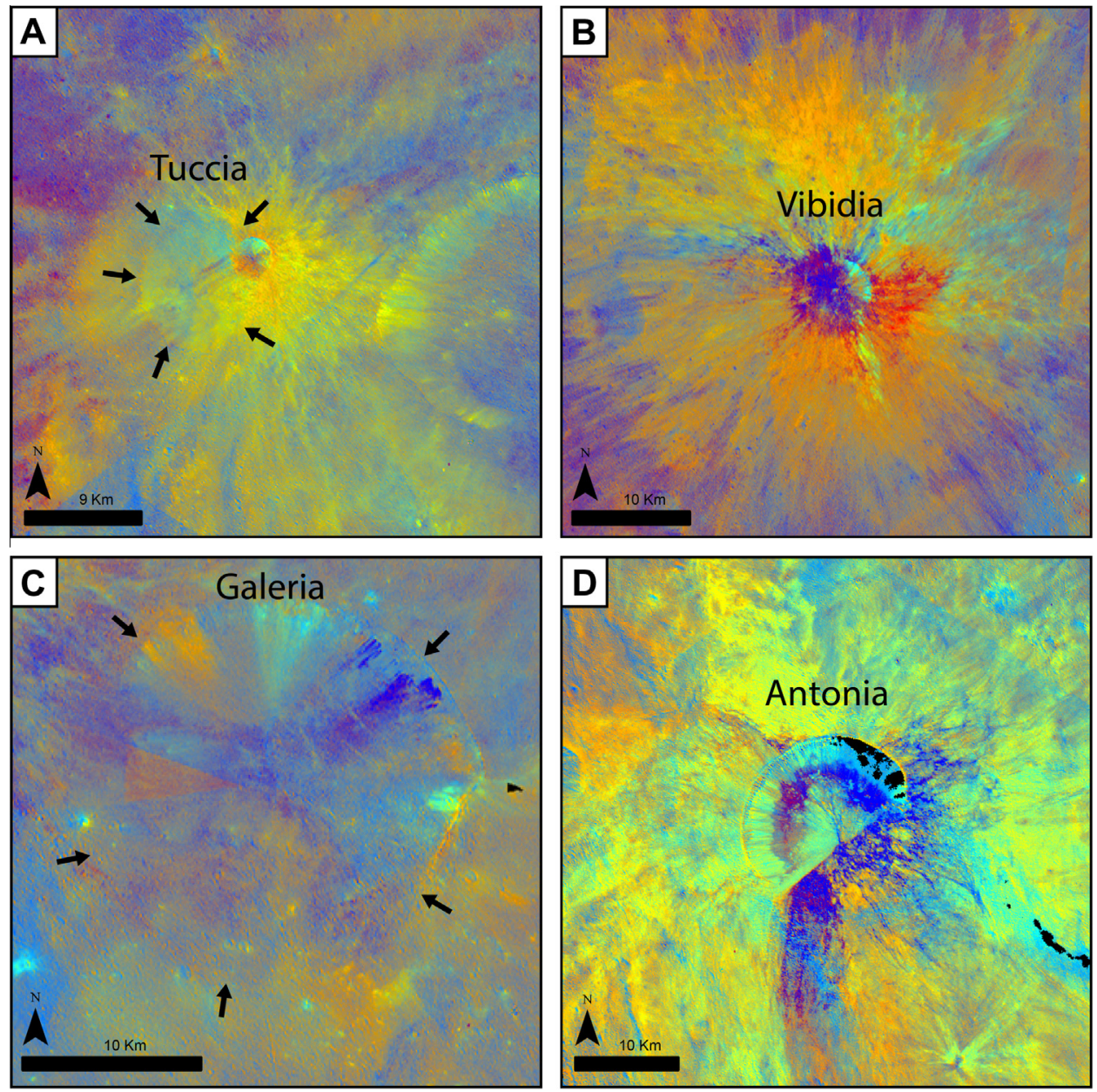

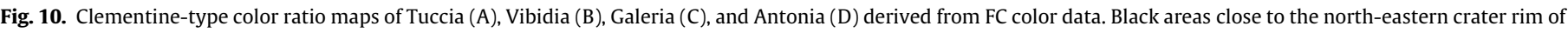
Antonia are due to shadow-related lack of data.

size seems to decrease with increasing distance from the crater rim. The block density is much higher within the crater bowl than outside.

Vibidia is a bright-rayed crater which, however, also excavated small amounts of dark material. This led to the deposition of complex crater ray material (ccr) on the floor of Vibidia and in close vicinity to the north-western crater rim (Fig. 6K). A possible outcrop of the dark material ejected by the Vibidia impact is the eastern crater wall, i.e., the crater wall escarping Vestalia Terra.

Vibidia shows three distinct compositional layers in color ratio maps (Fig. 10B). The blue colored material is the dark material that is thought to be remnant carbonaceous impactor material (Reddy et al., 2012a, 2012b) (see also Section 3.9). This material has an overall blue slope and subdued pyroxene absorption bands, which gives rise to the blue color in the color ratio image. The fresh material with deeper pyroxene bands manifests itself as green/cyan color in Fig. 10B. Based on the depth of the pyroxene absorption this material is thought to be in situ, predominantly diogenitic in nature. The bright orange material is similar to those seen around larger impact craters such as Oppia in the northern hemisphere. Le Corre et al. (2013) interpreted this material as impact melt. Based on the distribution of material around Vibidia one can hypothesize a few scenarios for its formation. In scenario A, the dark material and the impact melt would have been delivered/formed during the formation of the larger basins (Veneneia or Rheasilvia) and the impactor that formed Vibidia simply excavated this subsurface material. In scenario B, a small dark carbonaceous impactor excavated the bright material and during this process created the impact melt seen around Vibidia. The impact velocity in this scenario is critical because it has to be slow enough for the impactor material to survive but still high enough for impact melt production (Reddy et al., 2012a).

Galeria crater, located approx. $30 \mathrm{~km}$ east of Vibidia at $30.1^{\circ} \mathrm{S}$ and $228.2^{\circ} \mathrm{E}$, is also an asymmetric crater with a sharp, pristine crater rim on the northern crater side and a degraded rim on the southern (see Fig. 11D). Galeria has a diameter of $24.0-24.7 \mathrm{~km}$ and is located on the edge of the scarp bounding Vestalia Terra. Almost the complete southern and western rim is heavily affected by erosion or by asymmetric crater ejecta emplacement. Only the north-eastern part (approx. one quarter) of the rim is pristine/ sharp.

Like Vibidia, Galeria crater exhibits outcrops of dark material on the crater wall escarping Vestalia Terra. Here, the dark material is located in layers or lenses approximately $500-1300 \mathrm{~m}$ below the north-eastern crater rim, which is in agreement with the global average found by Yingst et al. (2013). Patchy dark material from these outcrops is moving downhill towards the crater center.

In addition to the degraded state of the morphology, the FC-color data also indicate an older age of Galeria relative to Vibidia. The crater ejecta are not so fresh as is evident from the lack of greenish diogenite-rich material that is typical of other fresh impact craters (Fig. 10C). Distinct patches of orange and blue material in the color ratio maps dominate the crater walls. The blue material here is the exogenous carbonaceous material similar to Vibidia (Reddy et al., 

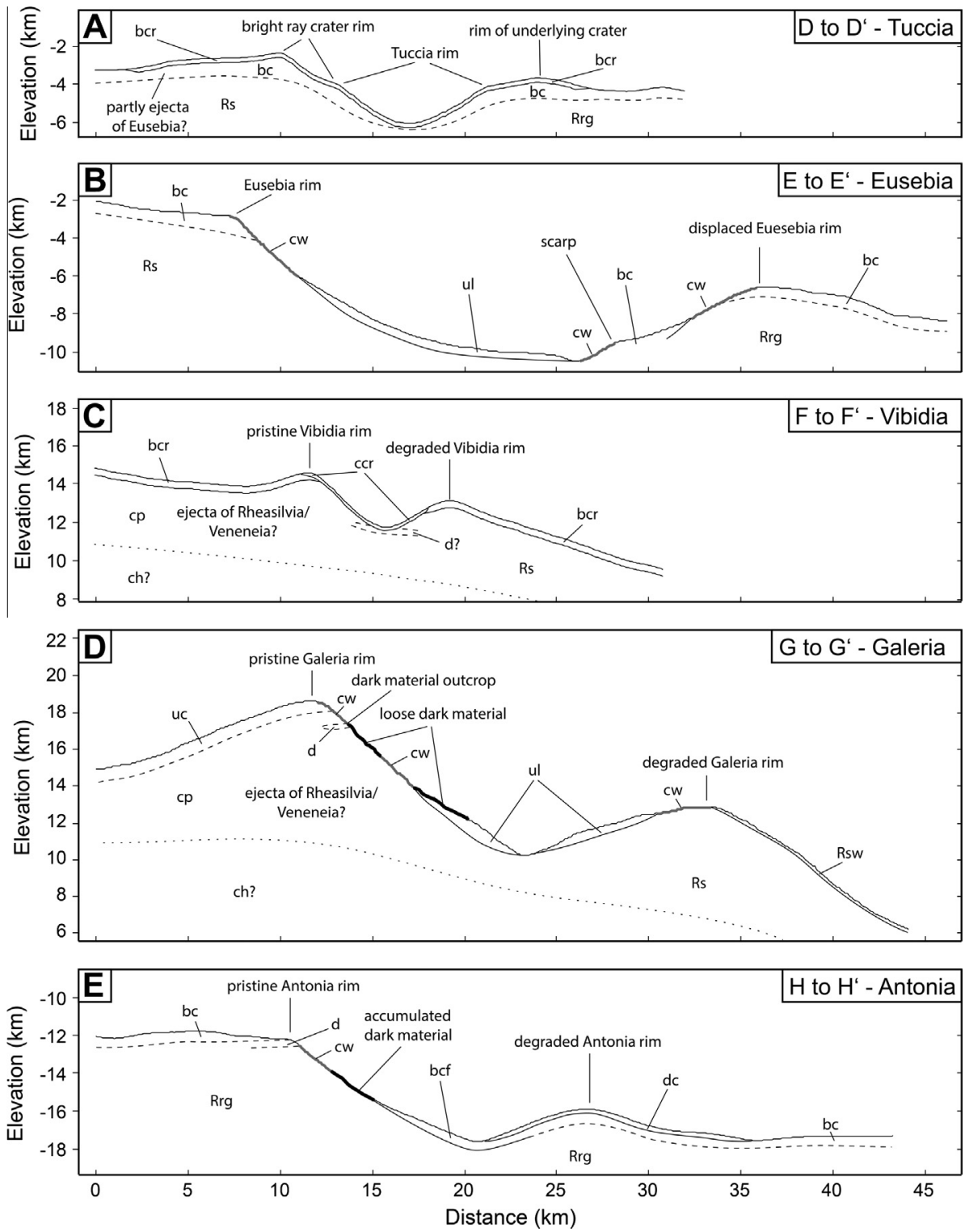

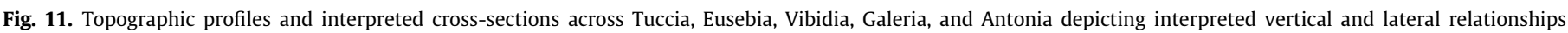

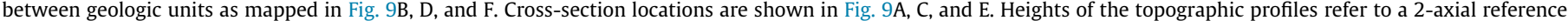
ellipsoid of $285 \times 229 \mathrm{~km}$ (radii) and have no vertical exaggeration.

2012a) and the orange material might be of impact melt origin (Le Corre et al., 2012a, 2013). All three color units appear to originate from a subsurface layer that is exposed along the crater walls due to mass wasting forming the landslide deposits on the crater floor.

\subsubsection{Age of Vibidia crater}

Because superposed impact craters on the bowl-shaped crater floor can be easily erased by slope-related mass wasting processes like creep, we only measured CSFDs on the almost planar craterejecta blankets of Vibidia. In order to account for local differences and compare the results, two opposing areas have been chosen as shown in Fig. 9C. Both CSFD measurements (IDs 8a, b; Fig. 13A) show clear resurfacing signatures. Because craters of larger diameters (approx. $>400 \mathrm{~m}$ in the southern measurement [ID $8 \mathrm{~b}$, green squares] and $>200 \mathrm{~m}$ in the northern measurement [ID 8a, black squares]) are heavily modified by superimposed ejecta, these crater sizes are interpreted to provide information about the age of the underlying unit. The resulting ages for the underlying terrain of $843 \pm 320 \mathrm{Ma}$ in the south and $915 \pm 210 \mathrm{Ma}$ in the north are comparable and provide overlapping error bars. The left part of the curves, i.e., fresh superposed craters with diameters of approx. $<100 \mathrm{~m}$ in the southern and $<80 \mathrm{~m}$ in the northern measurement, report the age of the ejecta blanket itself. The resulting ages of $10.5 \pm 0.7 \mathrm{Ma}$ (ID 8a) and 8.69 $\pm 0.38 \mathrm{Ma}$ (ID 8b) reflect the minimum age for the Vibidia impact formation (see also Section 5).

\subsubsection{Age of Galeria crater}

Because three-quarters of the crater rim is heavily degraded due to its location on the scarp of Vestalia Terra and because the crater floor is modified or covered by slump and landslide deposits, the determination of the formation age of Galeria is complicated. However, the adjacent area close to the north-eastern rim, i.e., a part of the Vestalia Terra terrain that is covered by ejecta of Galeria, is almost planar and, thus, provides a promising basis for a reliable age determination (ID 9a, Fig. 9C). The measured CSFD is shown in Fig. 13B and follows the expected production function consistently over $\sim 11$ crater bins. The resulting age of approx. $225 \pm 16 \mathrm{Ma}$ (ID 

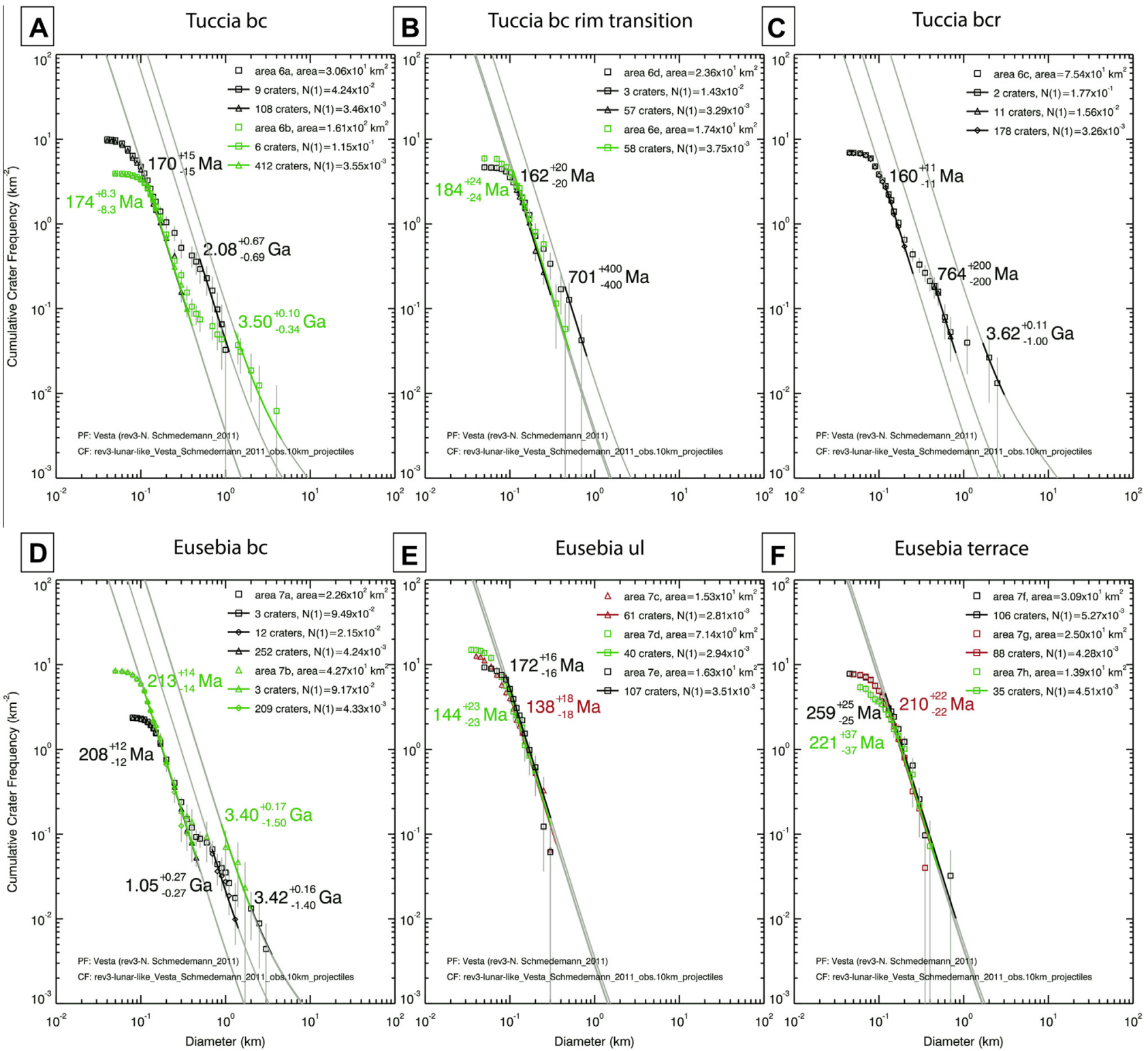

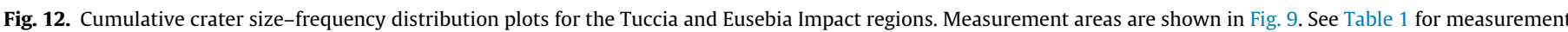
details.

9a) likely reflects the formation age of the Galeria crater (see also Section 5).

\subsection{Geology of Antonia crater}

Antonia is located at $60^{\circ} \mathrm{S}$ and $200^{\circ} \mathrm{E}$ with a diameter of approximately $14.8-15.6 \mathrm{~km}$. Antonia is situated close to the region with the lowest elevation on Vesta, with depths of approx. $21 \mathrm{~km}$ below the reference ellipsoid. The floor of Antonia itself is approximately $17.6 \mathrm{~km}$ below the reference ellipsoid. Like many other impact craters on Vesta, Antonia's morphology appears to be heavily affected by the underlying topography. Antonia shows a sharp, un-degraded crater rim in the up-slope direction (north) and a highly degraded/covered crater rim in the down-slope direction (south). In contrast to most of the other asymmetric craters, the loose material covering the southern rim of Antonia has a lower albedo than the surrounding material.

The bright ejecta blanket (unit bc) surrounding the crater exhibits typical ejecta morphologies like radial, linear, smooth surface features (see Fig. 6L). The top-most part of the northern crater wall of Antonia seems to consist of an approximately $400 \mathrm{~m}$ thick layer of dark (low-albedo) material (unit d). However, this outcrop has a higher albedo than the dark material outcrops at the scarp of Vestalia Terra. The dark layer at Antonia's northern crater wall possibly superimposes a thin layer of brighter material (see Fig. 14A and $\mathrm{C}$ ). The dark material seems to have moved downslope as a fine-grained material and accumulated on lower parts of the crater slope. The floor of Antonia, i.e., the lowest parts of the crater walls, is covered by two different types of crater floor materials. The western portion of the crater floor material is a relatively smooth, bright deposit and was mapped as bright crater floor material (bcf, Fig. 6R). In addition to the crater floor this material also covers parts of the western rim of Antonia and even a small area outside the crater. Unit bcf seems to be partly covered by the dark material (d) moving downslope. Furthermore, it is superposed by unit dc. The eastern part of the crater floor material has a lower albedo than the western and, thus, it was mapped as dark crater floor material (dcf, Fig. 6Q). However, it is still brighter than the material covering the southern rim of Antonia (dc). Furthermore, it has a rougher texture than unit bcf and shows lobe-shaped structures 
indicating down-slope movement. Following Krohn et al. (2013), the dark loose material covering the southern rim of Antonia is likely ejecta emplaced asymmetrically due to an impact on a steep slope. This material was mapped as dark crater material (dc) and consists of a mixture of dark and bright patches. Unit dc is located in the south-west, south, south-east, east, and partly north-east of Antonia. There is also a small occurrence of this material in the north-west of Antonia. The contact between dc and bcf on the crater floor indicates that dc superimposes bcf. Due to the fact that bcf can also be found on parts of the rim and outside the crater we interpret unit bcf to have been asymmetrically ejected by the impact process similarly to the dark crater material (dc). This might indicate that two layers of ejecta were emplaced on the southern rim, first unit bcf followed by unit dc. Impact craters with two or more ejecta layers have also been observed on the surface of Mars (e.g., Barlow et al., 2000). They are interpreted to be tied to ejectafluidization processes (e.g., Carr et al., 1977; Gault and Greeley, 1978) likely caused by vaporization of subsurface volatiles (e.g., Carr et al., 1977; Wohletz and Sheridan, 1983) or an interaction of the ejecta with the martian atmosphere (Schultz and Gault,
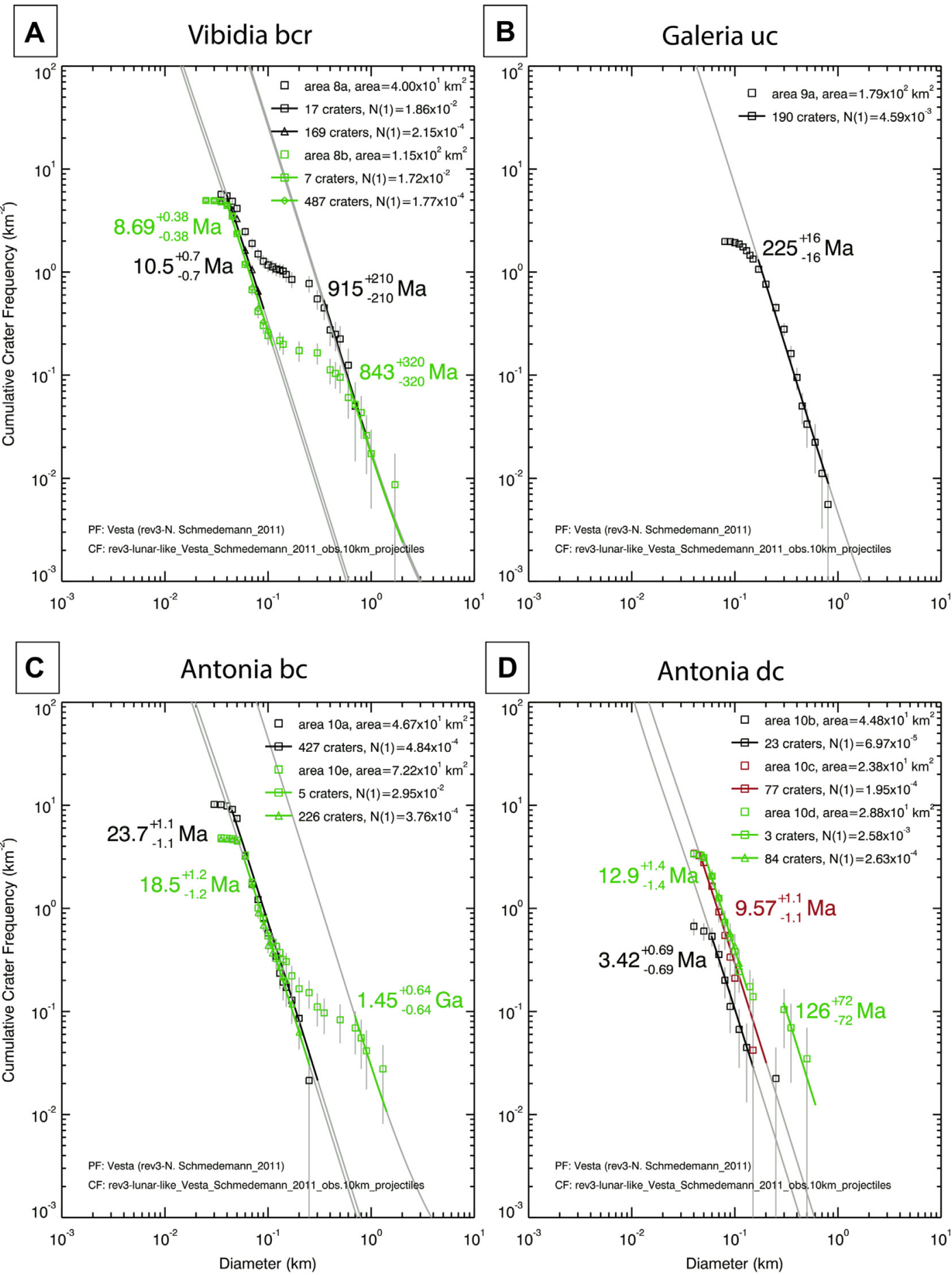

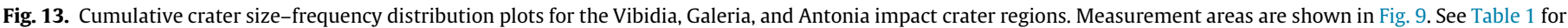
measurement details. 
1979; Barnouin-Jha and Schultz, 1998). However, as a result of the ejecta-fluidization martian multi-layer craters show distinct morphologies, such as lobate deposits and distal ridges (ramparts) (e.g., Carr et al., 1977). These morphologies have not been observed on Vesta. Thus, it is rather unlikely that the ejecta blanket of Antonia can be explained by the mechanisms mentioned above. The two different ejecta deposits of Antonia might be the result of the interaction of an impact on a steep slope and different layers in the target region. However, this is highly speculative and has to be tested in detail, e.g., by improved numerical modeling.

The observed morphologies and stratigraphic relationships of the local units led to the following interpretations/conclusions regarding the sequence of events in the Antonia region.

(1) The Rheasilvia ridge-and-groove material ( $R r g$ ) at least locally exhibits layers/patches of relatively dark material that might be seen on top of the northern crater wall of Antonia.

(2) The Antonia impact on a slope led to the asymmetrical emplacement of at least two layers of ejecta. The first one consists of bright material and is still visible on the western part of the crater floor (unit bcf) as well as on the plateau surrounding Antonia (bc). The second ejecta layer is darker (unit dc) and overlays the first layer (Fig. 11E). The dark component of this mixed material might originate from the dark material layer at the top-most part of the northern crater wall. Alternatively, the dark material could have been excavated from the deeper subsurface of Antonia and the dark layer at the top-most part of the northern crater wall may consist of dark ejecta material comparable that on the southern crater rim.

(3) The darker crater floor material in the eastern part of Antonia's floor might be a mixture of dark and bright ejecta material which originally was emplaced on the north-eastern crater wall (the part of the crater wall that is located beneath the north-eastern occurrence of unit dc). This material probably moved downslope towards the crater center leading to the rough texture and the lobe-shaped features.

(4) Finally, the latest and possibly ongoing process is the gravity-driven down-slope movement and accumulation of dark, fine-grained material from the outcropping dark layer on the top of the northern crater wall.

In order to constrain the surface composition and identify the origin and nature of the dark material in the Antonia region we used the Clementine-like color ratio maps. In the color ratio images (Figs. 10D and 14D), the dark crater material (unit dc), the dark material layer on the top of the northern crater wall, and the accumulated dark material in the mid-range of the crater slope appear bluish indicating a weaker visible spectral slope and shallower absorption band depth (Reddy et al., 2012b). Color spectra of the dark material confirm the findings of the color ratio maps.

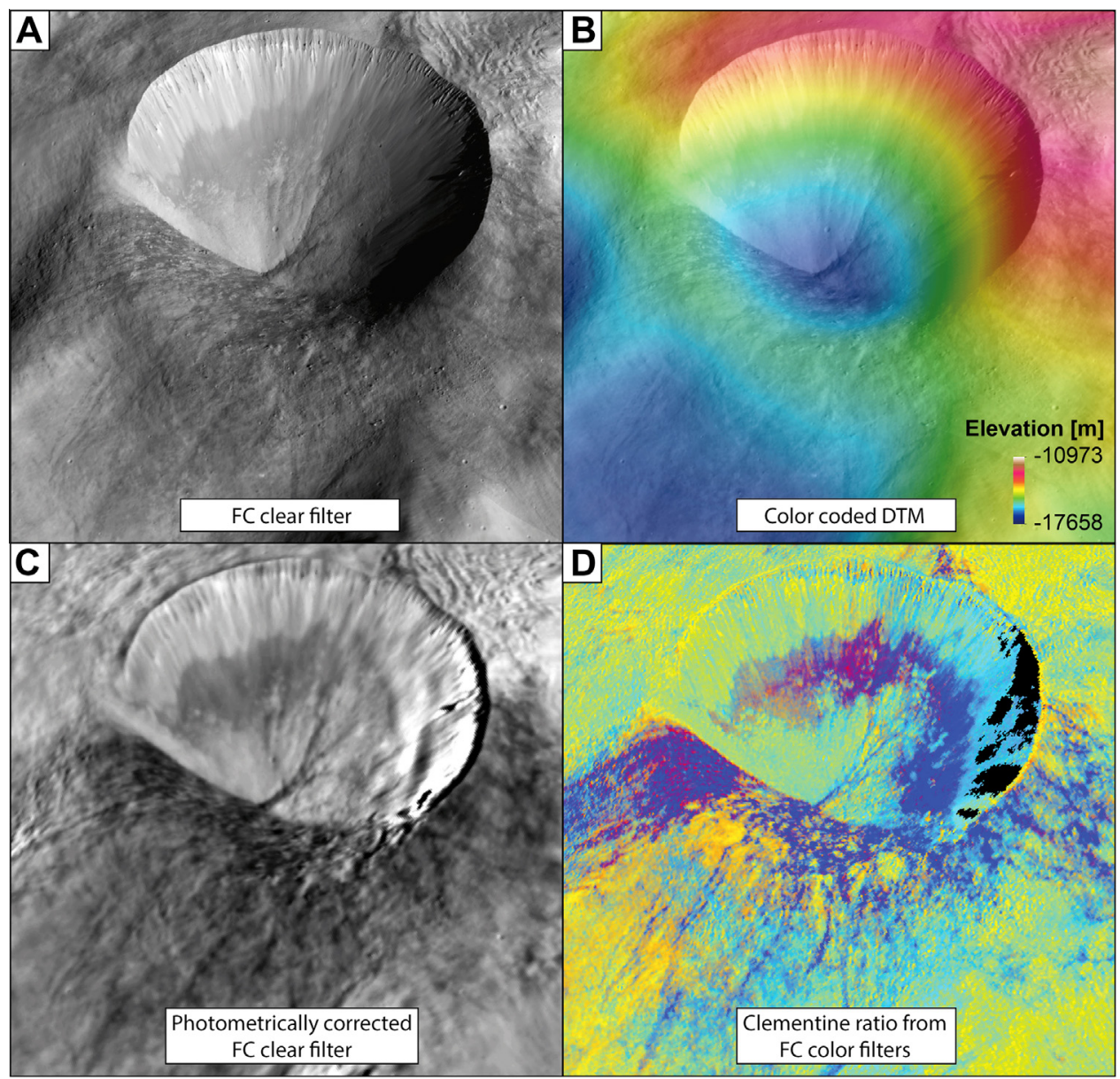

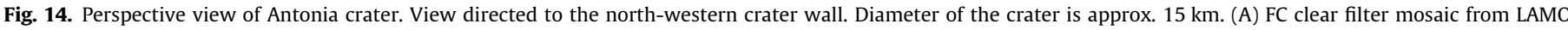

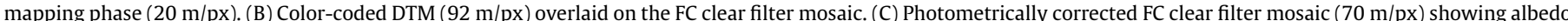

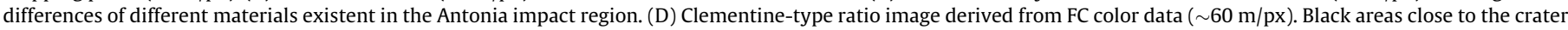
rim on the right-hand side of Antonia are due to a shadow-related lack of data. 
Normalized color spectra of the dark material, bright material from the crater wall and global surface average of Vesta are shown in Fig. 15. The spectra were normalized to unity at $0.75 \mu \mathrm{m}$. The average reflectance of $\mathrm{d}$, dc, and dcf material at $0.75 \mu \mathrm{m}$ is $7 \%$, in contrast the average reflectance of bcf is at $16 \%$ and $29 \%$ for cw. A plot of reflectance vs. absorption band depth shows that the three types of material form a continuum with the $\mathrm{cw}$ material being the most pristine and $\mathrm{d}$, dc, dcf being the darker, likely exogenous material. The impact mixing of these material leads to the formation of the intermediate bcf material.

Compositional analysis of these three units suggests that the cw material is pristine surface regolith primarily of howarditic composition and the d, dc, dcf material is linked to remnant exogenous carbonaceous chondrite impactor (McCord et al., 2012; Reddy et al., 2012a) (see also Section 3.9). Mixing of these end members due to impact gardening and seismic shaking gives rise to the intermediate bcf material.

\subsubsection{Age of Antonia crater}

Crater size-frequency distributions were measured on the eastern and western ejecta blanket (bc) of Antonia as well as on the dark ejecta material (dc) located inside Antonia and in close vicinity to the southern crater rim. Locations of the CSFD measurement areas (IDs 10a-e) are shown in Fig. 9E. The age of the underlying terrain can be determined using the larger craters $(>1 \mathrm{~km})$ that are still visible through the ejecta blanket. These craters provide an age of $1.45 \pm 0.64 \mathrm{Ga}$ (ID 10e, Fig. 13C). The age of the ejecta blanket itself and, thus, of the impact of Antonia, was determined to be between $\sim 18.5 \pm 1.2 \mathrm{Ma}$ (ID 10e) and $23.7 \pm 1.1 \mathrm{Ma}$ ago (ID 10a). The slightly different ages of these two measurements might be a result of local variations in target properties, the application of the resurfacing correction, or a slight difference in the fitting range. We interpret these measurements to indicate a formation age of Antonia of $\sim 20$ Ma ago (see also Section 5 ). This relatively young age of Antonia is consistent with the fresh-looking morphology, i.e., the sharp rim of the northern part of Antonia and the high number of boulders in the Antonia region. The age derived on the dark ejecta material (unit dc) inside and south of Antonia is lower (3.42 $\pm 0.69 \mathrm{Ma}$ [ID 10b], $9.57 \pm 1.4 \mathrm{Ma}$ [ID 10c], $12.9 \pm 1.4$ Ma [ID 10d]) (see Fig. 13D) than on the ejecta blankets east and west (ID 10a and ID 10e, respectively) indicating that the material was modified after the formation of Antonia, possibly due to gravity-driven mass wasting processes. Alternatively, the young ages might be a result of the difficulty of crater identification on this rough, low-albedo unit. The less distinct age of $126 \pm 72 \mathrm{Ma}$ (ID 10d) as determined in one of the measurements on the southern deposits might reflect a different resurfacing event in the Antonia impact region.

\section{Discussion}

\subsection{The age of Rheasilvia}

Marchi et al. (2012) and Schenk et al. (2012a) proposed a formation age for Rheasilvia of $\sim 1 \pm 0.2$ Ga mainly based on a CSFD measurement of the entire floor of Rheasilvia. Applying the chronology function (CF) and production function (PF) of O'Brien et al. and Marchi et al. to our measurement on unit Rrg (area ID 3a) we derived an age of $\sim 1.12 \mathrm{Ga}+128 /-129 \mathrm{Ma}$ on the floor of Rheasilvia that is more or less consistent with the original measurement by Marchi et al. (2012) and Schenk et al. (2012a). This indicates that there is no major difference in the crater identification and measurement techniques between their CSFD measurements and the measurements carried out in this work. When using the CF and PF of Schmedemann et al. (submitted for publication), the same
CSFD measured on the floor of Rheasilvia (unit Rrg) provides a surface age of $2.31 \mathrm{Ga} \pm 320 \mathrm{Ma}$ (ID 3a) (see stratigraphic column in Fig. 7). Because of the fact that the CF by Schmedemann et al. (submitted for publication) and the CF by O'Brien et al. (submitted for publication) are nearly identical over the time range from the present back to $\sim 3 \mathrm{Ga}$ ago, the age difference for unit Rrg is mainly the result of the different PFs. Regardless of which chronology system is used for the age determination of the floor of Rheasilvia, it should be expected that CSFDs on the surface of Rheasilvia's ejecta do not show ages higher than the formation age of Rheasilvia. The Rheasilvia smooth material (unit Rs) has been interpreted to be emplaced/formed by the Rheasilvia impact (Yingst et al., 2013). As described in Section 3.3, CSFDs on unit Rs differ from east to west (see Fig. 5C). The surface age of the eastern part of Rs is comparable to the age of unit Rrg (Rrg: $2.31 \pm 0.32$ Ga [ID 3a]; Rs: $2.47 \mathrm{Ga}+0.55 /-0.63 \mathrm{Ga}$ [ID 2a] using the CF and PF of Schmedemann et al.). However, on the western part of unit Rs, i.e., on the former floor of the Veneneia basin that was heavily re-shaped/ modified by the Rheasilvia impact event (Schenk et al., 2012a), the CSFD indicates a surface age higher than the ridge-and-groove material $(3.46+0.09 /-0.22$ Ga for Rs [ID 2b] and $2.31 \pm 0.32 \mathrm{Ga}$ for $\mathrm{Rrg}$ ). The shape of the CSFD might suggest that there was a resurfacing process that ended $\sim 1.7 \mathrm{Ga}$ ago (ID $2 \mathrm{~b}$ ). This resurfacing signature might imprudently be interpreted to be caused by the Rheasilvia impact. However, except for one unnamed crater, the morphology of the craters responsible for the definition of the higher age, i.e., craters in the diameter range between 5 and $20 \mathrm{~km}$, do not show any evidence of mantling by extraneous ejecta material. Thus, Rheasilvia and its ejecta cannot have been responsible for the resurfacing signature at $\sim 1.7 \mathrm{Ga}$. Furthermore, Schenk et al. (2012a) stated that the Rheasilvia impact obliterated all preexisting craters $\leq 20 \mathrm{~km}$ to a distance of $50 \mathrm{~km}$ from the Rheasilvia rim, i.e., most of our CSF measurement area for this unit. Thus, the CSFD on that part of the floor of Veneneia has to be as young as or younger than the Rheasilvia basin indicating that the Rheasilvia basin has to be older than $3.46+0.09 /-0.22 \mathrm{Ga}$, i.e. much older than suggested by the CSFD on the basin floor. Consequently, the floor of the Rheasilvia basin must have been subsequently modified, probably by large-scale mass wasting/resurfacing processes.

Furthermore, it is important to emphasize that this main conclusion does not change if the chronology system by O'Brien et al. and Marchi et al. is used (ages in the right column in Fig. 7). Applying this system one gets an age of $3.8 \mathrm{Ga}+0.5 /$ $-1.3 \mathrm{Ga}$ for unit Rs on the floor of Veneneia much older than the

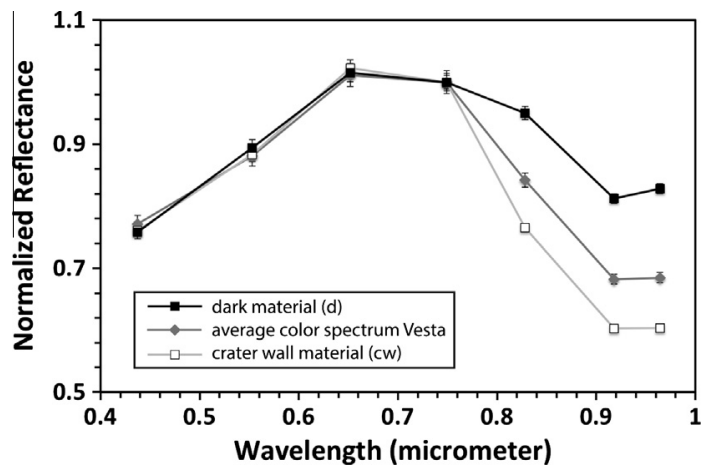

Fig. 15. Color spectra of dark material (black) and bright material from the crater wall (light gray) of Antonia along with average color spectrum of Vesta (dark gray). The spectra were normalized to unity at $0.75 \mu \mathrm{m}$. Dark material has weaker absorption band depth than brighter material from crater walls. The mixing of these compositionally distinct materials gives rise to an intermediate albedo material similar to bcf/dcf material. 
age of $\sim 1.1 \mathrm{Ga}+0.1 /-0.1 \mathrm{Ga}$ as derived from the basin floor (unit Rrg).

Comparable to the measurement on the floor of Veneneia, the two measurement areas for unit cp are located directly at the rim of Rheasilvia and, thus, these measurements might help to further constrain the formation age of Rheasilvia. Both measurements provide surface ages higher than that determined on unit Rrg. However, due to their small measurement areas and the accordingly low numbers of large craters, both measurements show very large age uncertainties $(2.99+0.37 /-1.10 \mathrm{Ga}$ [ID $1 \mathrm{~b}$ ] and $3.41+0.15 /-1.10$ Ga [ID 1a]) and, thus, these measurements do not help to constrain the formation age of Rheasilvia more precisely.

\subsection{Prominent mid-sized impact craters}

Vincent et al. (2013) observed that the beginning of the transition from simple to complex craters on Vesta might be seen at $\sim 38 \mathrm{~km}$. Consequently, all craters investigated in this study (8$27 \mathrm{~km}$ ) should have been formed as simple, bowl-shaped craters. This is in agreement with our morphological observations, i.e., they are missing central peaks or peak rings.

Vibidia and Antonia represent the least degraded craters among the craters investigated in this study. They show relatively pristine crater rims, typical fresh ejecta features, as well as high numbers of boulders/blocks in the close vicinity to the craters. Furthermore, the ejecta blankets of both craters have a strong greenish appearance in the color ratio maps indicating fresh diogenite-rich material (see Sections 2.1 and 3.8, Reddy et al., 2012a, 2012b). These findings are consistent with their young formation ages as derived through CSFD analyses. Tuccia also shows a relatively pristine crater rim. Its ejecta, however, lack the strong spectral signature observed for Vibidia and Antonia. Only the regions covered by the fresh ejecta deposits of the much younger bright-rayed crater on Tuccia's rim are clearly visible in the color ratio maps. Eusebia and Galeria show much more degradation than Vibidia, Antonia, and Tuccia. They already show a rich variety of mass wasting deposits like slumps and landslides on their crater floors and the linear features on their ejecta blankets are less distinct. The ejecta of Eusebia are less distinct in the color ratio map than the ejecta of Vibidia or Antonia. The greenish appearance of Galeria's ejecta at the scarp and on the plateau of Vestalia Terra has almost completely vanished. Generally, the degradation state and appearance in the color ratio data of the five prominent craters investigated in this study are consistent with their relative age sequence as derived from CSFD analyses. This confirms the general suitability of the usage of small-scale crater populations for (at least) relative age determinations. However, local CSFD variations on ejecta blankets partly complicate the determination of stratigraphic relationships as they sometimes provide a relatively wide range of possible formation ages. For instance the sequence of Eusebia (208 $\pm 12 \mathrm{Ma}$ to $259 \pm 25 \mathrm{Ma}$ [ID 7a, b, f, g, h]) and Galeria (225 $\pm 16 \mathrm{Ma}$ [ID 9a]) is not unambiguous from CSF data, although color ratio data indicate that Galeria is probably older than Eusebia.

Concerning the absolute crater formation ages it is remarkable that all the determined ages are in the range between $10 \mathrm{Ma}$ and $260 \mathrm{Ma}$, i.e., all the investigated craters seem to have formed relatively recently. Several scenarios are considered for this accumulation of relatively young crater formation ages:

(A) One possibility is that the resurfacing signatures on the ejecta blankets of Tuccia, Eusebia, Vibidia, and Antonia, which were interpreted to represent the formation ages of the craters, are actually caused by other, subsequent resurfacing events. However, as already described in Sections 4.1.1 and 4.1.2 there are no craters observed in close vicinity to, e.g., Tuccia or Eusebia, whose ejecta emplacement or seismic shaking could be responsible for the resurfacing signatures observed in the CSFDs of Tuccia and Eusebia. The only explanation for the distinct resurfacing signatures that are consistent without the influence of an additional impact crater would be large-scale gravity-driven mass movement in the interior of Rheasilvia. However, such an event would create a homogeneous age signature over the whole area instead of two different signatures surrounding Tuccia and Eusebia, respectively. The same applies to the resurfacing signatures on the ejecta of Antonia. If the obliteration of the small-diameter craters had been caused by a large-scale mass wasting event, the $\sim 20$ Ma-resurfacing age signature should also appear in the close-by Tuccia-Eusebia region, but it does not. Thus, we interpret the resurfacing signatures on the ejecta blankets to represent the formation ages of the respective craters.

(B) A second explanation for the high frequency of young craters in the Tuccia quadrangle is the influence of the chronology system used for the age extraction. As described above, we made use of the system of Schmedemann et al. (submitted for publication) and derived ages in the range between $10 \mathrm{Ma}$ and $260 \mathrm{Ma}$. Using the chronology system of O'Brien et al. (2012) and Marchi et al. (2013) the same CSFD measurements result in older crater formation ages ranging from $\sim 50 \mathrm{Ma}$ for Vibidia up to $\sim 900 \mathrm{Ma}$ for Eusebia (see also Table 1 and Fig. 7). As described in Section 2.2, the two CFs are almost identical for younger surfaces ( $<3 \mathrm{Ga}$ ) and, thus, the resulting age difference is mainly due to the shape of the PF curves. However, the slope of the PF by Marchi et al. (2013) is too shallow in order to properly fit several undisturbed, steep CSFDs measured on the ejecta blankets. Three CSFD measurements on Antonia, Galeria, and Eusebia, all without resurfacing signatures, are shown in Fig. 16. The steeper PF of Schmedemann et al. (submitted for publication) (black solid and dashed line) seems to fit better to these CSFD than the shallower PF of Marchi et al. (gray solid and dashed line), suggesting that the PF of Schmedemann et al. is closer to reality. Moreover, the CSFD measurement on the ejecta blanket of Galeria, which seems morphologically to be one of the oldest of the investigated craters, includes craters up to a diameter of $830 \mathrm{~m}$, which is very close to the reference diameter of $1 \mathrm{~km}$ used in the CFs (see Fig. 16B). Consequently, the influence of the PF shape is reduced for this specific measurement, because the measurement does not need to be extrapolated very far in order to reach the reference diameter of the CF. Therefore, the resulting age difference between the two systems is relatively low $(225 \pm 16 \mathrm{Ma}$ compared to $323+106 /-107 \mathrm{Ma})$. As described above, the degradation state of Galeria indicates that it should be older or at least in the same age range as the fresher-looking Tuccia and Eusebia craters. Using the chronology system of O'Brien et al. (2012) and Marchi et al. (2013), the ages derived for Tuccia and Eusebia are in the range of $\sim 600-900 \mathrm{Ma}$, much older than the age derived for Galeria. The results from the chronology system of Schmedemann et al. (submitted for publication) seem to be more consistent with the crater sequence indicated by the degradation state of the craters.

(C) The third and probably simplest possibility is that the high frequency of young crater ages is due to the fact that only the morphologically remarkable/prominent impact craters were investigated in this study. The Tuccia quad additionally contains several less conspicuous mid-sized impact craters, like the one that is superposed by the Tuccia impact, the craters at the base of the southern scarp of Vestalia Terra, or the 

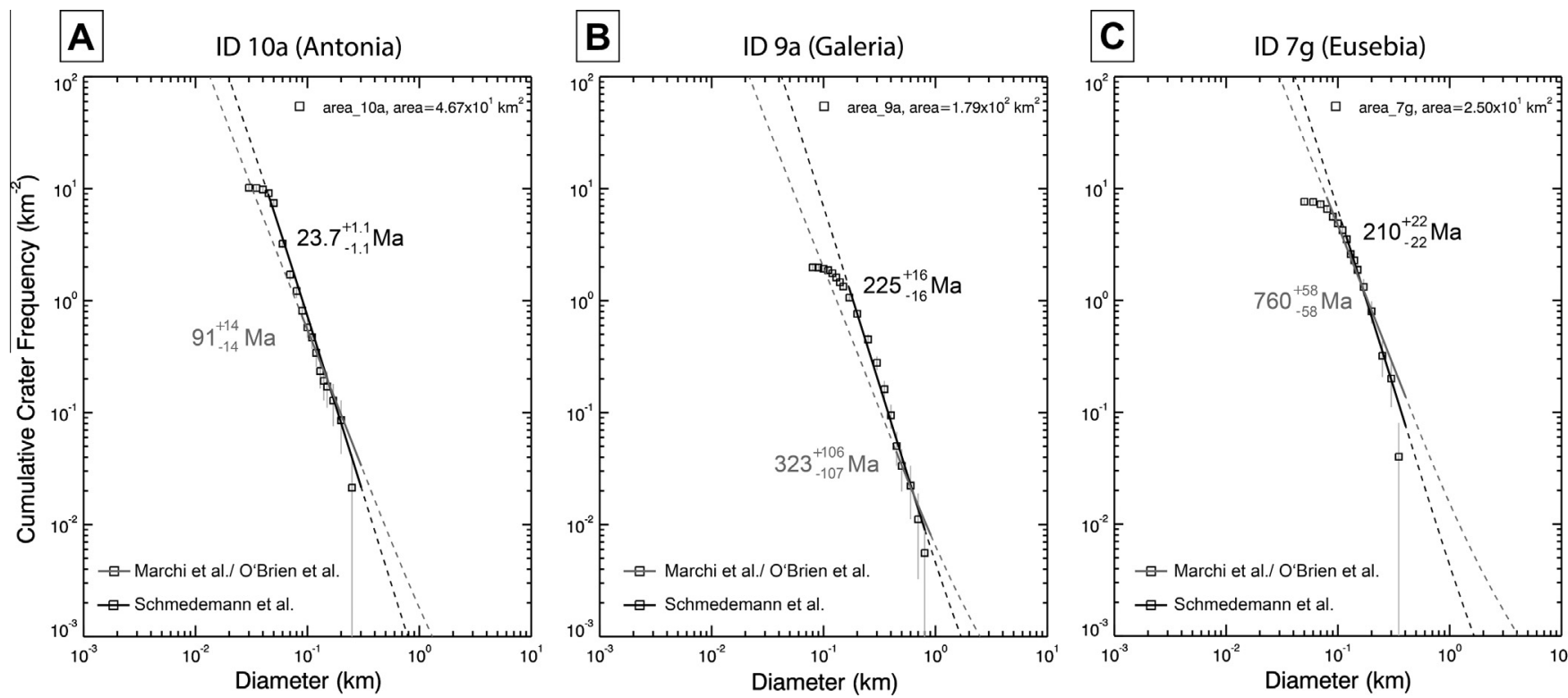

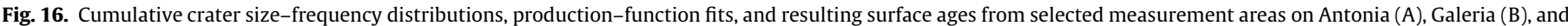

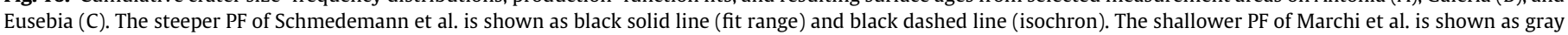
solid and dashed lines, respectively.

heavily degraded impact structures north of Antonia. Their degraded morphologies indicate formation ages much older than $260 \mathrm{Ma}$. Unfortunately, it is almost impossible to date the degraded impact structures, because their ejecta blankets and crater floors are completely covered by subsequent ejecta and/or modified by slump/landslide events. This prevents a closer look at the absolute age distribution of all mid-sized craters found in the quadrangle. However, the determined $d / D$ ratios are in agreement with the proposed scenario. Except for Eusebia, whose crater rim and floor was heavily modified by the substantial displacement of the southern rim, all investigated mid-sized craters show higher $d / D$ ratios than the average value of the quadrangle $(\emptyset=0.195, n=34$, using all craters larger than Vibidia $(8.2 \mathrm{~km}))$.

Irrespective of the relative age distribution, the high frequency of young $(<300 \mathrm{Ma})$ mid-sized craters in quadrangle Tuccia is in agreement with the high cratering rate on Vesta, which is $\sim 24$ times higher than the cratering rate on the Moon (O'Brien et al., submitted for publication; Schmedemann et al., submitted for publication). Here, the shape of the PF of Schmedemann et al. predicts a total number of $\sim 39$ craters larger than $10 \mathrm{~km}$ and younger than $300 \mathrm{Ma}$ over the entire surface of Vesta. The shallower PF by Marchi et al. even predicts $\sim 70$ craters of this age and size. No matter which model is used, both of them indicate that young ( $<300 \mathrm{Ma}$ ) mid-sized craters are no rarity on the surface of Vesta. This prediction gets support by the first age determinations in other regions (mapping quadrangles) of Vesta showing comparable young age results for several prominent mid-sized craters (Le Corre et al., 2013; Ruesch et al., this issue; Williams et al., this issue-a). Ruesch et al. (this issue) determined the ages of seven prominent impact craters ( $\sim 11$ to $\sim 63 \mathrm{~km}$ in diameter) in the northern hemisphere of Vesta. Four of them show ages less than $200 \mathrm{Ma}$, the others are $\sim 370, \sim 470$, and $\sim 630$ Ma old. The prominent crater Marcia (58 $\mathrm{km}$ ) seems to be $\sim 120-150 \mathrm{Ma}$ old (Williams et al., this issue-a) and the craters Oppia (34 km) and Octavia (30 km) are $\sim 270$ Ma and $\sim 370$ Ma old (Le Corre et al., 2013).

Assuming our determined crater formation ages are realistic, the advanced state of ejecta degradation seems remarkable considering the relatively young formation ages of Eusebia and Galeria of less than 2300 Ma. This might be explained by the high impact rate on Vesta, which probably speeds up the physical degradation of ejecta features. Additionally, impacts in low-gravity fields of small bodies produce more widespread, discontinuous ejecta deposits and less continuous ejecta blankets compared to the same impact event in a high-gravity environment of a large planet (e.g., Cintala et al., 1978; Bogard, 1995). These thinner deposits might be degraded much faster by subsequent impact gardening or gravity-driven mass wasting processes than thicker continuous ejecta blankets. Additionally, the process of "space weathering" seems to be completely different on the surface of Vesta from the Moon (Pieters et al., 2012). The accumulation of nanophase iron particles, which is believed to be responsible for the weakening of specific absorption bands on the Moon (Pieters et al., 2000) and other airless bodies (Hapke, 2001), seems to be absent on the surface of Vesta (Pieters et al., 2012). Instead of the accumulation of nanophase metallic particles, small-scale regolith mixing seems to be the driving force for space weathering (Pieters et al., 2012). This different form of space weathering in combination with diffuse/thinner ejecta blankets and the higher impact rate might explain the high degradation state and the lack of strong spectral signatures of relatively young impact crater ejecta on the surface of Vesta.

\section{Conclusions}

- Dark-material outcrops in Vibidia, Galeria, and in other, older impact craters at the southern/south-eastern scarp of Vestalia Terra indicate that dark material exists in layers or lenses in the subsurface of Vestalia Terra. This is consistent with the proposed emplacement mechanism for dark material within Veneneia ejecta as proposed by Reddy et al. (2012a) and Jaumann et al. (2012a).

- Age differences between the Rheasilvia floor and regions adjacent to the Rheasilvia rim indicate extensive subsequent modifications of the interior of the basin probably due to gravitydriven mass wasting processes. CSFDs on the Rheasilvia smooth material (Rs) indicate a formation age of Rheasilvia older than $3.4 \mathrm{Ga}$ (using the lunar-like PF and CF by Schmedemann 
et al.) or $\sim 3.8 \mathrm{Ga}$ (using the functions by O'Brien and Marchi et al.). This is in agreement with the findings of Schmedemann et al. (submitted for publication) and in disagreement with Marchi et al. (2012) and Schenk et al. (2012a).

- Several young landslide and slump deposits in the interior of Rheasilvia, as well as age differences between the ejecta of the investigated craters and the deposits on their floors (e.g., the lobate deposits in Eusebia) indicate ongoing gravity-driven mass wasting processes in the Rheasilvia region and in midsized craters on Vesta.

- All investigated impact craters show very young crater retention ages in the range of $\sim 10 \mathrm{Ma}$ to $\sim 260 \mathrm{Ma}$ (using the lunar-like PF and CF by Schmedemann et al.). This is consistent with the high cratering rate on Vesta.

- Although relatively young (<300 Ma), Galeria and Eusebia already show relatively diffuse ejecta blankets that are barely spectrally visible. This might be explained by the high impact rate on Vesta combined with the formation of more discontinuous, thinner ejecta deposits on the low-gravity body.

- Vibidia and Antonia show the youngest ages of 10-20 Ma, consistent with their pristine morphology and appearance in Clementine-type color ratio data. The agreement between degradation state and surface ages derived from CSFDs confirms the usability of small-scale CSF analysis for, at least, relative surface age determinations.

\section{Acknowledgments}

The authors acknowledge the support of the Dawn Science, Instrument and Operations Teams. This research has made use of the USGS Integrated Software for Imagers and Spectrometers (ISIS). We thank Michael Zanetti and an anonymous reviewer for the comments and suggestions, which helped improve the manuscript. This work was partly supported by the German Space Agency (DLR), Grant 50 OW 1101.

\section{Appendix Appendix}

Supplementary data associated with this article can be found, in the online version, at http://dx.doi.org/10.1016/j.icarus.2014. 02.012 .

\section{References}

Archinal, B.A. et al., 2011. Report of the IAU working group on cartographic coordinates and rotational elements: 2009. Celes. Mech. Dynam. Astron. 109, 101-135.

Arvidson, R., 1979. Crater analysis techniques working group - Standard techniques for presentation and analysis of crater size-frequency data. Icarus 37, 467-474.

Barlow, N.G. et al., 2000. Standardizing the nomenclature of martian impact crater ejecta morphologies. J. Geophys. Res. 105, 26733-26738.

Barnouin-Jha, O.S., Schultz, P.H., 1998. Lobateness of impact ejecta deposits from atmospheric interactions. J. Geophys. Res. 103, 25739-25756.

Becker, K.J., Anderson, J.A., Barrett, J.M., Sides, S.C., Titus, T.N., 2012. ISIS support for Dawn instruments. Lunar Planet. Sci. 43. Abstract \#2892.

Binzel, R.P., Gaffey, M.J., Thomas, P.C., Zellner, B.H., Storrs, A.D., Wells, E.N., 1997. Geologic mapping of Vesta from 1994 Hubble Space Telescope images. Icarus 128, 95-103.

Bogard, D. 1995. Impact ages of meteorites: A synthesis. Meteoritics 30, 244-268.

Buchanan, P.C., Zolensky, M.E., Reid, A.M., 1993. Carbonaceous chondrite clasts in the howardites Bholghati and EET87513. Meteoritics 28, 659-669.

Buczkowski, D.L. et al., this issue. The geology of Vesta quadrangle Av-9 Numisia: Evaluating the unique geomorphology and physical properties of the Vestalia Terra plateau. Icarus.

Carr, M.H., Crumpler, L.S., Cutts, J.A., Greeley, R., Guest, J.E., Masursky, H., 1977. Martian impact craters and emplacement of ejecta by surface flow. J. Geophys. Res. 82, 4055-4065.

Cintala, M.J., Head, J.W., Veverka, J., 1978. Characteristics of the cratering process on small satellites and asteroids. Proc. Lunar Sci. Conf. 9, 3803-3830.
Gault, D.E., Greeley, R., 1978. Exploratory experiments of impact craters formed in viscous-liquid targets - Analogs for martian rampart craters. Icarus 34, 486495.

Hapke, B., 2001. Space weathering from Mercury to the asteroid belt. J. Geophys Res. 106, 10039-10074.

Hartmann, W.K., 1971. Martian cratering III: Theory of crater obliteration. Icarus 15 $410-428$.

Hartmann, W.K., Werner, S.C., 2010. Martian cratering 10. Progress in use of crater counts to interpret geological processes: Examples from two debris aprons. Earth Planet. Sci. Lett. 294, 230-237.

Hiesinger, H., Head, J.W., Wolf, U., Jaumann, R., Neukum, G., 2002. Lunar mare basalt flow units: Thicknesses determined from crater size-frequency distributions. Geophys. Res. Lett. 29, 1248.

Hiesinger, H. et al., 2013. Geologic map of the northern hemisphere of Vesta based on Dawn FC Images. Lunar Planet. Sci. 44. Abstract \#2582.

Jaumann, R. et al., 2012a. The geological context of Vesta's dark material. American Geophysical Union (Fall), vol. 24. Abstracts \#1477775.

Jaumann, R. et al., 2012b. Vesta's shape and morphology. Science 336, 687-690.

Kneissl, T., van Gasselt, S., Neukum, G., 2011. Map-projection-independent crater size-frequency determination in GIS environments-New software tool for ArcGIS. Planet. Space Sci. 59, 1243-1254.

Kneissl, T. et al., 2013. Prominent impact craters in the AV-13 quadrangle Tuccia on Vesta-Morphology, degradation, and ages of Tuccia, Eusebia, Vibidia, Galeria, and Antonia. Lunar Planet. Sci. 44. Abstract \#1078.

Krohn, K. et al., 2012. Geologic mapping of the Av-12 Sextlia quadrangle of Asteroid 4 Vesta. Lunar Planet. Sci. 43. Abstract \#1901.

Krohn, K. et al., 2013. Bimodal craters on Vesta: Impacts on slopes studied by geological investigations. Lunar Planet. Sci. 44. Abstract \#1949.

Krohn, K. et al., this issue. Mass movement on Vesta at steep scarps and crater rims. Icarus.

Le Corre, L., Reddy, V., Nathues, A., Cloutis, E.A., 2011. How to characterize terrains on 4 Vesta using Dawn Framing Camera color bands? Icarus 216, 376-386.

Le Corre, L. et al., 2012a. Nature of orange ejecta around Oppia and Octavia craters on Vesta from Dawn Framing Camera. AAS/Division for Planetary Sciences Meeting, vol. 44 (Abstracts).

Le Corre, L. et al., 2012b. Vesta terrains seen by the Dawn Framing Camera color filters. Lunar Planet. Sci. 43. Abstract \#1624.

Le Corre, L. et al., 2013. Olivine or impact melt: Nature of the "Orange" material on Vesta from Dawn. Icarus 226, 1568-1594.

Li, J., 2012. Body-fixed coordinate systems for Asteroid (4) Vesta. <http:/ sbn.psi.edu/archive/dawn/fc/DWNVFC2_1A/DOCUMENT VESTA_COORDINATES/VESTA_COORDINATES_131018.PDF>.

Marchi, S. et al., 2012. The violent collisional history of Asteroid 4 Vesta. Science 336, 690-694.

Marchi, S. et al., 2013. Small crater populations on Vesta. Planet. Space Sci. http:// dx.doi.org/10.1016/j.pss.2013.05.005.

McCord, T.B. et al., 2012. Dark material on Vesta from the infall of carbonaceous volatile-rich material. Nature 491, 83-86.

McGetchin, T.R., Settle, M., Head, J.W., 1973. Radial thickness variation in impact crater ejecta: Implications for lunar basin deposits. Earth Planet. Sci. Lett. 20, 226-236.

McSween, H.Y., Mittlefehldt, D.W., Beck, A.W., Mayne, R.G., McCoy, T.J., 2011. HED meteorites and their relationship to the geology of Vesta and the Dawn mission. Space Sci. Rev. 163, 141-174.

Mest, S.C. et al., 2012. Geologic mapping of the Av-14 Urbinia quadrangle of Asteroid 4 Vesta. Lunar Planet. Sci. 43. Abstract \#2375.

Michael, G.G., 2013. Planetary surface dating from crater size-frequency distribution measurements: Multiple resurfacing episodes and differential isochron fitting. Icarus 226, 885-890.

Michael, G.G., Neukum, G., 2010. Planetary surface dating from crater sizefrequency distribution measurements: Partial resurfacing events and statistical age uncertainty. Earth Planet. Sci. Lett. 294, 223-229.

Nass, A., van Gasselt, S., Jaumann, R., Asche, H., 2011. Implementation of cartographic symbols for planetary mapping in geographic information systems. Planet. Space Sci. 59, 1255-1264.

Nathues, A., Le Corre, L., Reddy, V., Hoffmann, M., Team, D.S., 2012. Identification of Vesta surface units with principal component analysis by using Dawn Framing Camera imagery. Lunar Planet. Sci. 43. Abstract \#1779.

Neukum, G., Hiller, K., 1981. Martian ages. J. Geophys. Res. 86, 3097-3121.

Neukum, G., Horn, P., 1976. Effects of lava flows on lunar crater populations. Moon $15,205-222$

O'Brien, D. P., et al., submitted for publication. Constraining the Cratering Chronology of Vesta. Planet. Space Sci.

O’Brien, D.P., 2013. Personal communication.

O'Brien, D.P., Marchi, S., Schenk, P., Russell, C.T., Raymond, C.A., 2012. The impact history of Vesta: Developing and testing an absolute cratering chronology. Lunar Planet. Sci. 43. Abstract \#2688.

Otto, K.A. et al., 2013. Mass-wasting features and processes in Vesta's south polar basin Rheasilvia. J. Geophys. Res. 118, 2279-2294.

Pieters, C.M., Fischer, E.M., Rode, O., Basu, A., 1993. Optical effects of space weathering: The role of the finest fraction. J. Geophys. Res. 98, 20817-20824.

Pieters, C.M. et al., 2000. Space weathering on airless bodies: Resolving a mystery with lunar samples. Meteorit. Planet. Sci. 35, 1101-1107.

Pieters, C.M. et al., 2012. Distinctive space weathering on Vesta from regolith mixing processes. Nature 491, 79-82. 
Platz, T., Michael, G., Tanaka, K.L., Skinner, J.A., Fortezzo, C.M., 2013. Crater-based dating of geological units on Mars: Methods and application for the new global geological map. Icarus 225, 806-827.

Plescia, J.B., 2012. Impacts on sloping surfaces: Lunar examples. Meteorit. Planet. Sci. Suppl. 75. Abstract \#5318.

Preusker, F. et al., 2012a. Topography of Vesta from Dawn FC stereo images. Luna Planet. Sci. 43. Abstract \#2012.

Preusker, F. et al., 2012b. Topography of Vesta from Dawn FC stereo images. European Planetary Science Congress, vol. 7, \#428.

Preusker, F. et al., 2012c. Topography of Asteroid (4) Vesta from Dawn FC HAMO stereo images. EGU General Assembly Conference, vol. 14. Abstracts \#11805.

Raymond, C.A. et al., 2013. Vestalia Terra: An ancient Mascon in the southern hemisphere of Vesta. Lunar Planet. Sci. 44. Abstract \#2882.

Reddy, V., Gaffey, M.J., Kelley, M.S., Nathues, A., Li, J.-Y., Yarbrough, R., 2010. Compositional heterogeneity of Asteroid 4 Vesta's southern hemisphere: Implications for the Dawn mission. Icarus 210, 693-706.

Reddy, V. et al., 2012a. Delivery of dark material to Vesta via carbonaceous chondritic impacts. Icarus 221, 544-559.

Reddy, V. et al., 2012b. Color and albedo heterogeneity of Vesta from Dawn. Science 336, 700-704.

Richardson, J.E., Melosh, H.J., Greenberg, R.J., O’Brien, D.P., 2005. The global effects of impact-induced seismic activity on fractured asteroid surface morphology. Icarus 179, 325-349.

Roatsch, T. et al., 2012. High resolution Vesta High Altitude Mapping Orbit (HAMO) Atlas derived from Dawn Framing Camera images. Planet. Space Sci. 73, 283286.

Ruesch, O. et al., this issue. Geologic map of the northern hemisphere of Vesta based on Dawn Framing Camera (FC) images. Icarus.

Russell, C.T., Raymond, C.A., 2011. The Dawn mission to Vesta and Ceres. Space Sci. Rev. 163, 3-23.

Russell, C.T. et al., 2012. Dawn at Vesta: Testing the protoplanetary paradigm. Science 336, 684-686.

Schenk, P. et al., 2012a. The geologically recent giant impact basins at Vesta's south pole. Science 336, 694-697.

Schenk, P., Vincent, J.-B., O’Brien, D.P., Jaumann, R., Williams, D., 2012b. Impact crater morphologies on Vesta. European Planetary Science Congress, vol. 7. \#700.

Schmedemann, N. et al., 2012a. Crater size-frequency distribution (CSFD) and chronology of Vesta-Crater counts matching HED ages. Lunar Planet. Sci. 43. Abstract \#2544.

Schmedemann, N. et al., 2012b. Cratering on 4 Vesta - Comparison of crater retention ages and $\mathrm{Ar}-\mathrm{Ar}$ ages of HED meteorites. EGU General Assembly Conference, vol. 14. Abstracts \#9055.
Schmedemann, N., et al., submitted for publication. The Cratering Record, Chronology and Surface Ages of (4) Vesta in Comparison to Smaller Asteroids and Ages of HED meteorites. Planet. Space Sci.

Schultz, P.H., Gault, D.E., 1979. Atmospheric effects on martian ejecta emplacement. J. Geophys. Res. 84, 7669-7687.

Sierks, H. et al., 2011. The Dawn Framing Camera. Space Sci. Rev. 163, 263-327.

Thomas, P.C., Robinson, M.S., 2005. Seismic resurfacing by a single impact on the Asteroid 433 Eros. Nature 436, 366-369.

Thomas, P.C. Binzel, R.P., Gaffey, M.J., Storrs, A.D., Wells, E.N., Zellner, B.H., 1997. Impact excavation on Asteroid 4 Vesta: Hubble Space Telescope results. Science 277, 1492-1495.

Titley, S.R., 1966. Seismic energy as an agent of morphologic modification on the Moon. Tech. Rep. United States Geological Survey, Flagstaff, AZ

U.S.G.S., 2006. FGDC Digital Cartographic Standard for Geologic Map Symbolization (PostScript Implementation): U.S. Geological Survey Techniques and Methods 11-A2. <http://pubs.usgs.gov/tm/2006/11A02/>.

Vincent, J.-B., Besse, S., Marchi, S., Sierks, H., Massironi, M., Team, O., 2012a. Physical properties of craters on Asteroid (21) Lutetia. Planet. Space Sci. 66, 79-86.

Vincent, J.-B. et al., 2012b. Crater depth-to-diameter ratio and surface properties of (4) Vesta. Lunar Planet. Sci. 43. Abstract \#1415.

Vincent, J.-B. et al., 2013. Crater depth-to-diameter distribution and surface properties of (4) Vesta. Planet. Space Sci., http://dx.doi.org/10.1016/ j.pss.2013.09.003.

Werner, S.C., 2005. Major Aspects of the Chronostratigraphy and Geologic Evolutionary History of Mars. Fachbereich Geowissenschaften, Freie Universität Berlin, pp. 160.

Williams, D.A. et al., 2013. Lobate and flow-like features on asteroid Vesta. Planet Space Sci. http://dx.doi.org/10.1016/j.pss.2013.06.017.

Williams, D.A. et al., this issue-a. The geology of the Marcia quadrangle of asteroid Vesta: Assessing the effects of large, young craters. Icarus.

Williams, D.A., Yingst, R.A., Garry, W.B., this issue-b. Introduction: The geologic mapping of Vesta. Icarus.

Wohletz, K.H., Sheridan, M.F., 1983. Martian rampart crater ejecta - Experiments and analysis of melt-water interaction. Icarus 56, 15-37.

Yingst, R.A. et al., 2013. Geologic mapping of Vesta. Planet. Space Sci. http:// dx.doi.org/10.1016/j.pss.2013.12.014.

Zolensky, M.E., Weisberg, M.K., Buchanan, P.C., Mittlefehldt, D.W., 1996. Mineralogy of carbonaceous chondrite clasts in HED achondrites and the Moon. Meteorit. Planet. Sci. 31, 518-537. 